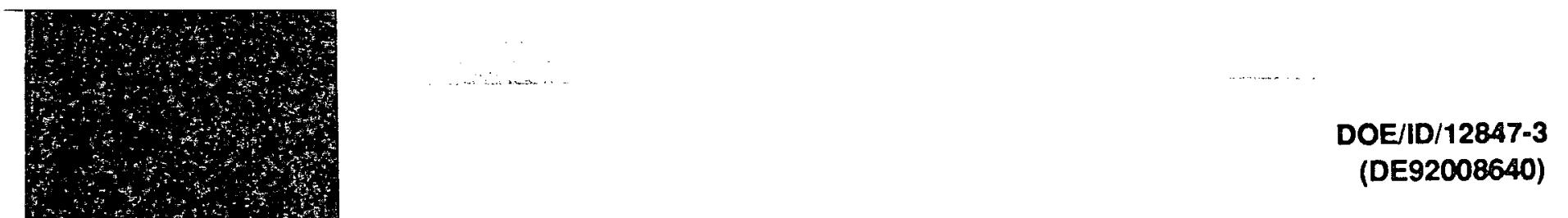

\title{
AISI DIRECT STEELMAKING PROGRAM
}

Annual Technlcal Report for Year Ending November 30, 1991

By

Agil Aukrust

January 1992

Work Performed Under Contract No. FC07-89ID12847

For

U.S. Department of Energy Office of Industrial Technologies Washington, D.C.

By American Iron and Steel Institute Washington, D.C. 


\section{DISCLAIMER}

This report was prepared as an account of work sponsored by an agency of the United States Government. Neither the United States Government nor any agency thereof, nor any of their employees, makes any warranty, express or implied, or assumes any legal liability or responsibility for the accuracy, completeness, or usefulness of any information, apparatus, product, or process disclosed, or represents that its use would not infringe privately owned rights. Reference herein to any specific commercial product, process, or service by trade name, trademark, manufacturer, or otherwise does not necessarily constitute or imply its endorsement, recommendation, or favoring by the United States Government or any agency thereof. The views and opinions of authors expressed herein do not necessarily state or reflect those of the United States Government or any agency thereof.

This report has been reproduced directly from the best available copy.

Available to DOE and DOE contractors from the Office of Scientific and Technical Information, P.O. Box 62, Oak Ridge, TN 37831; prices available from (615)576-8401, FTS 626-8401.

Available to the public from the National Technical Information Service, U.S. Department of Commerce, 5285 Port Royal Rd., Springfield, VA 22161. 


\section{DISCLAIMER}

This report was prepared as an account of work sponsored by an agency of the United States Government. Neither the United States Government nor any agency Thereof, nor any of their employees, makes any warranty, express or implied, or assumes any legal liability or responsibility for the accuracy, completeness, or usefulness of any information, apparatus, product, or process disclosed, or represents that its use would not infringe privately owned rights. Reference herein to any specific commercial product, process, or service by trade name, trademark, manufacturer, or otherwise does not necessarily constitute or imply its endorsement, recommendation, or favoring by the United States Government or any agency thereof. The views and opinions of authors expressed herein do not necessarily state or reflect those of the United States Government or any agency thereof. 


\section{DISCLAIMER}

Portions of this document may be illegible in electronic image products. Images are produced from the best available original document. 


\title{
AISI DIRECT STEELMAKING PROGRAM \\ Annual Technical Report for Year Ending November 30, 1991
}

January 1992

Work Performed Under Contract FC07-891D12847

\author{
Prepared for the \\ U.S. Department of Energy \\ Under DOE Idaho Field Office \\ Sponsored by the Office of the Assistant Secretary \\ for Conservation and Renewable Energy \\ office of Industrial Technologies \\ Washington, D.C.
}

Prepared by

American Iron and Steel Institute

Washington, D.C.

This document is

PUBJICLY RELEASABLE

8 anz Steele

Authorizing official

Date: $\quad 4-3.07$ 
2 mentide

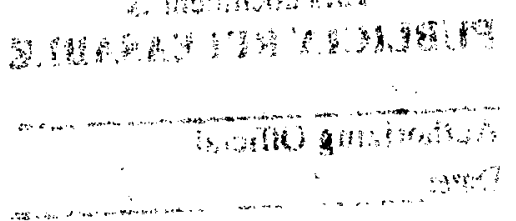




\section{ANNUAL TECHNICAL REPORT \\ AIBI - DOE Direct steelmaking Program}

Section

Page

Summary

Research Program

Task 1 - Physical Chemistry studies - CMU

Task 1 - Physical Chemistry studies - MIT 11

Task 2 - Continuous Refining 20

Task 3 - Smelter Operation 20

Task 4 - Mathematical and Physical Modeling 47

Task 4 - $\begin{gathered}\text { Physical Models, Heat Transfer, } \\ \text { Parametric Models }\end{gathered}$

Task 6 - Technoeconomic Analysis 61

Task 7 - Patents, Talks, Publications 62

Task 8 - Physical Modeling of the Two-zone Smelter 65

Task 9 - Design and Construction of the Horizontal

Task 10 - Design of a Moving-bed Shaft Reducer 68

Task 12 - Mannesmann Demag Basic Study 70 


\section{AI8I/DOE DIRECT BTEELMARING ANNUAL REPORT}

\section{BUMMARY}

The Direct steelmaking Program has completed the third year of research and development since cost-share funding was provided by the Department of Energy. The physical chemistry programs conducted by Carnegie Mellon University (CMU) and the Massachusetts Institute of Technology (MIT) have been completed. A pilot plant has been constructed and successfully operated at Universal, Pennsylvania, and construction of a new, two-zone vessel pilot plant has been completed and trial operation is underway. The success of the pilot plant operation coupled with the development of process models involving reaction rates, heat-transfer and fluid-flow rates, and mass and energy balances has led to a basic study of a 350,000 tonne per year demonstration plant that gives promise of being a low capital and operating cost alternative for ironmaking as compared to the coke oven, blast furnace process. It has the further advantages of ease of startup and shutdown, lower energy consumption, and modularity so that capacity can be adapted to need.

The physical chemistry programs at CMU and MIT studied fundamental reactions among ore, coal, flux, slag, metal droplets, and the liquid metal bath. Work at CMU centered on slag foaming studies, coal devolatilization, dissolution of hematite and wustite pellets in bath smelting slags, reduction of Feo in slag by char, extent of reverse or depostcombustion reactions in postcombustion gases, and developing an overall smelting model. Salient results are that sulfur in the slag above about $0.1 \%$ adversely affects bubble size and foaming index; $40 \%$ postcombustion with good heat transfer should be obtainable, even with a high-volatility coal; dissolution of both hematite and wustite pellets is rapid (less than 10 seconds) in slags at smelter operating temperatures; and depostcombustion reactions should be minimized. An overall smelting model has been developed for a single-zone vessel in terms 
of the useful volume of the vessel and the slag-foam volume, which varies with pressure. The analysis indicates production intensities of 9.6 and 15 tonnes $/ \mathrm{m}^{3}$ day at one and three atmospheres, respectively, should be obtainable based on AISI pilot plant results.

Work at MIT included studies of melting of hematite and wustite pellets in molten slag; pyrolysis and solution of coal, coke, and graphite in Fe-C melts; studies of reduction rates of $\mathrm{FeO}$ in $\mathrm{Fe}-\mathrm{C}$ melts; and the reaction of Fe-C droplets with Feo in molten slag. Experimental results of the pellet-melting studies agreed with mathematical model results and indicated that melting of the pellets would be rapid at operating slag temperatures and would not be of concern in the smelting process. The pyrolysis studies showed that recovery of carbon in the melt decreased as the volatility of the coal increased and that sulfur in the melt reduces the rate of solution of carbon in the melt. Reduction rates in the metal bath are rapid, especially at temperatures well above the liquidus, and reduction of Feo in the slag by $\mathrm{C}$ in Fe-C droplets is proportional to the Feo content of the slag.

Forty-nine trials were conducted at the pilot plant prior to shutdown at the end of August, 1991, to permit construction and installation of the two-zone horizontal vessel. The trials included seven types of coal; three sources of iron; two fluxes and various slag basicities; various oxygen lance positions, designs, and blow velocities; side injection of coal and of oxygen; various levels of char volume in the slag; different levels of bottom stirring with nitrogen; and twelve different refractory brick.

Instrumentation and sampling were continually improved throughout the campaign. For the latest trials, more than 7000 data points were logged into the database for each minute of operation. These ranged from online measurement of temperatures and raw material feed rates to relative and cumulative dust loading of $\mathrm{Fe}, \mathrm{Feo}, \mathrm{C}$, and $s$ in the stack-scrubber sludge measured for each run segment. 
Control strategies and operating procedures were developed that led to controlled periods of steady-state operation and rapid shifts to new steady-state operating conditions. Energy and mass balances were established with the help of dust-loading and volatile-matter bypass measurements and were used to convert actual coal rates to steady-state coal rates with recycle of dust that would take place in an integrated plant with cyclones and a shaft furnace and an offgas utilization system.

Refractory wear was acceptable, even under the severe operating conditions involving many startups and shutdowns and planned excursions in operating conditions.

Pilot plant operation indicated that phosphorus was within acceptable levels but that sulfur removal will be required. Most of the sulfur remains in. the gas phase so that gas desulfurization processes should suffice for environmental control. Future work will explore removal as hot $\mathrm{H}_{2} \mathrm{~S}$ in the smelter prereducer flowsheet or as $\mathrm{SO}_{2}$ in the final combustion gases.

The mathematical and physical modeling of heat transfer and fluid flow performed by personnel at McMaster and McGill have helped guide the pilot plant trials and have suggested variations in oxygen lance practices and in side injection practices. Union Carbide personnel have contributed to the mass and energy balance analysis of pilot plant data, to lance design, to refining practices applied in the technoeconomic analyses, and to understanding the role of fixed carbon and volatile matter from coals in the smelting process.

The technoeconomic analysis confirmed the promise developed in the original proposal that smelting should produce hot metal at a lower variable operating cost and with less energy consumption than the coke oven, blast furnace process. The simplicity of the process equipment gives the promise of lower capital cost, but capital costs were not estimated. The continuous nature of the process 
leads to some promising flowsheets for refining iron to steel using continuous desulfurization, as practiced in a General Motors foundry, and continuous decarbonization, as developed by IRSID.

The two-zone smelting process, that can lead to a lower-carbon iron (not $C$ saturated), gives promise of a variety of flowsheets leading to steel, including use of BOF, EAF, or AOD processes.

For this one-year reporting period, application was made for one patent (Two-Zone countercurrent Smelter). Five talks were given by program personnel at three different conferences, and two papers were published. Much of the work performed at CMU, MIT, McMaster, and McGill has been prepared for publication and should appear in society transactions in the upcoming year. The AISI-DOE Direct Steelmaking Research Program has been budgeted through Fiscal 1991 for $\$ 33,361,000$, of which $77 \%(\$ 25,661,000)$ has been funded by the federal government.

Physical modeling of the two-zone smelter by CMU and USS personnel at the USS Technical center has provided insight into the separation and mixing of the hot metal and slag between the two zones and guidance for the design of the pilot vessel as well as for the experimental program. The vessel construction and installation proceeded on schedule. Installation is now complete, and the vessel and its ancillary equipment are in the final checkout stage.

A moving-bed shaft reducer has been designed by HYLSA and specifications have been prepared for both a 10 tonne per hour and a 50 tonne per hour shaft furnace to operate by use of the smelter offgas.

Mannesmann Demag personnel have completed a basic study of the single-zone ironmaking process that confirms the promise established in the pilot plant operation. They have developed a design basis for a plant to produce 50 tonnes of hot metal per hour 
with a vertical smelter operating at a pressure of three atmospheres and a shaft furnace according to HYLSA's design. Their analysis indicates that capital and operating costs compare favorably with that for iron made by a blast furnace. A more detailed feasibility study for a demonstration plant will be the next step.

\section{TABR 1 - PHYSICAL CHEMISTRY 8TUDIES - CMU}

\section{Slag Foaming}

This year's work was primarily concerned with foams generated from chemical reactions and the effect of coal char on foaming. The major results are as follows:

1. The foams generated by chemical reaction consist of small bubbles $(1 \sim 5 \mathrm{~mm})$. The reaction of interest is

$$
(\mathrm{FeO})+\underline{\mathrm{C}}(\text { in } \mathrm{Fe})=\mathrm{CO}+\mathrm{Fe}
$$

As shown in Figure 1, the bubble size depends on the sulfur content of the metal. This can be explained by the effect of sulfur on the interfacial energy. For bath smelting metal the bubbles are expected to be about $4-5 \mathrm{~mm}$.

2. The foam index, which is proportional to the foam height, is inversely proportional to the bubble size, as shown in Figure 2.

3. Foam heights were accurately predicted for the actual bath smelting process based on the laboratory results. 


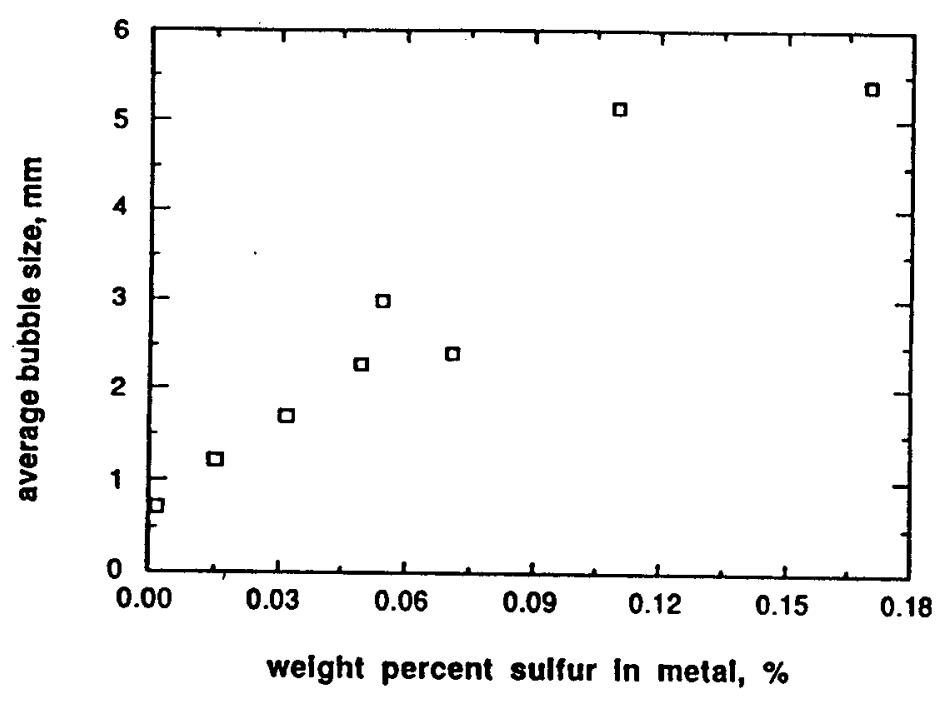

Figure 1. Bubble size of foams generated by slag/metal Interiacial reaction as a function of sulfur content in metal phase.

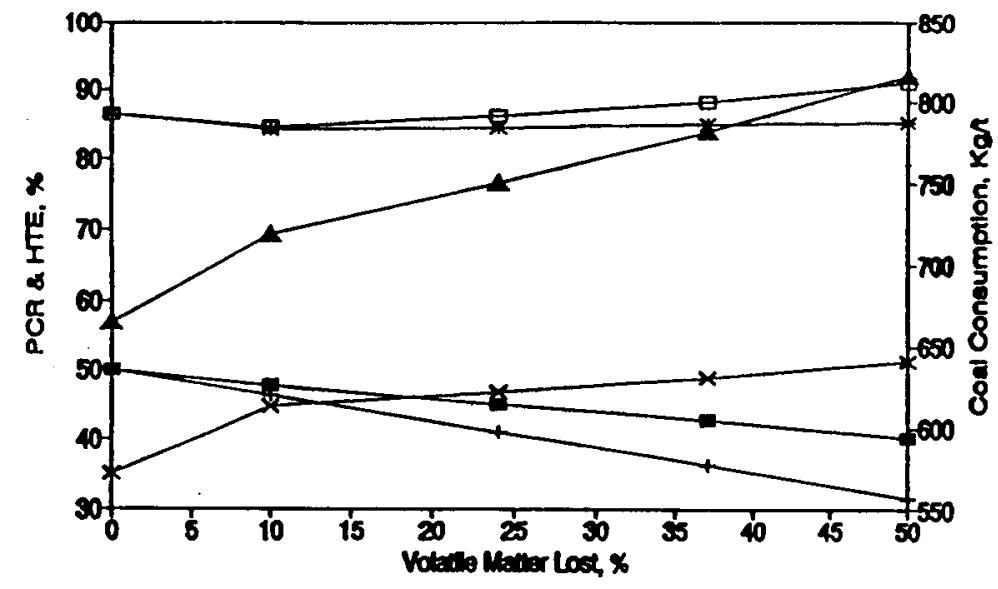



Figure 3 . Coal consumption, HTE, and PCR as a function of volatiles lost.



Figure 2. Relationship between the foam index and the average bubble size.



$43.78 \times \mathrm{V}$

$+$

$19.70 \times 64$

Figure 4. HTE as a function of PCR for different VM coals and comparison to NSC data. 


\section{Devolatilization of Coal}

The experimental results were previously reported. The work this year was on developing a model of the smelting system to predict the effect of coal devolatilization on coal consumption, postcombustion, and heat transfer. The model considered two zones, the smelting system and the top gas system, and separate energy and material balances were conducted for each zone. In the top gas zone, preheating, dehydration, and devolatilization of the coal were considered.

From the results of the model it is clear that coal reactions in the top gas affect the degree of postcombustion (PCD), heat transfer efficiency (HTE), and coal consumptions as shown in Figure 3. The model was also able to explain the Japanese results, Figure 4, and the decrease in heat transfer efficiency with increasing degree of postcombustion.

\section{Dissolution of Oxide Pellets in Bath Smelting Slag}

This task is complete, and a report has been submitted to AISI. Briefly, the rate of solution of commercial $\mathrm{Fe}_{2} \mathrm{O}_{3}$ and Feo pellets was measured by visual observation of the dissolution by $x$-ray video. The effects of gas stirring and preheating were also examined. The results are summarized below.

1. In unstirred melts, $\mathrm{Fe}_{2} \mathrm{O}_{3}$ dissolved faster than $\mathrm{FeO}$ due to the release of $\mathrm{O}_{2}$ which stirred the slag and increased heat transfer.

2. In stirred melts, Feo dissolved faster than $\mathrm{Fe}_{2} \mathrm{O}_{3}$, and at $1450^{\circ} \mathrm{C}$ dissolution took 30 and 50 seconds, respectively, as shown in Figure 5 . 


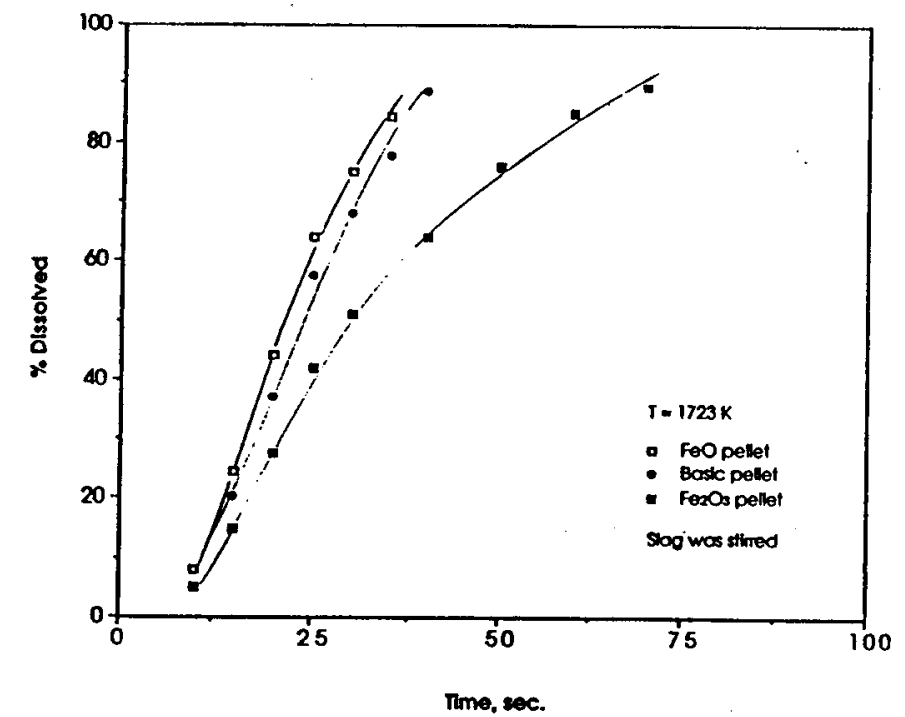

Figure 5 . Rate of dissolution of a wustite, a hematite and a basic pellet in $40 \% \mathrm{CaO}$ $40 \% \mathrm{SiO}_{2}-20 \% \mathrm{Al}_{2} \mathrm{O}_{3}$ slag at $1723 \mathrm{~K}$.



1. Coke sphere: Diameter $=1.5 \mathrm{~cm}: 2$. Coke sphere : Diameter $=1.42 \mathrm{~cm}$

3. Graphite sphere : Diameter $1.33 \mathrm{~cm}: 4$ Graphite sphere : Diameter $=1.29 \mathrm{~cm}$

Figure 7. Mass transfer coefficient vs evolution rate per unit area for reduction by graphite and coke spheres

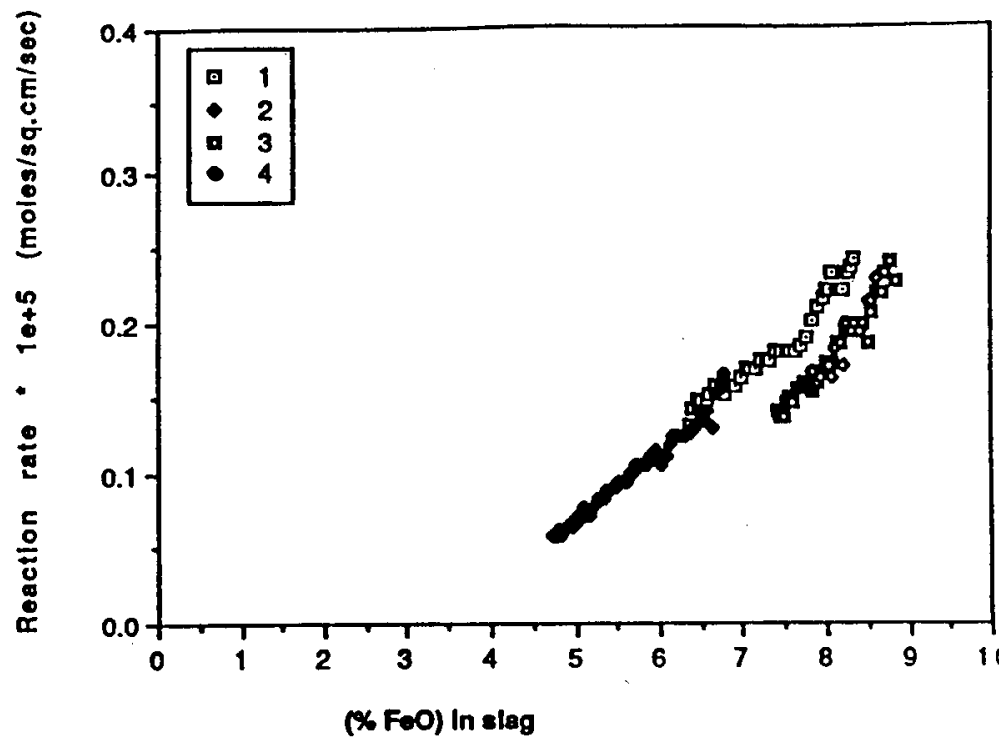

1. Coke sphere : Diameter $=1.5 \mathrm{~cm}: 2$. Coke sphere : Diameter $=1.42 \mathrm{~cm}$

3. Graphile sphere: Diameter $=1.33 \mathrm{~cm}: 4$. Graphite sphere : Diameter $=1.29 \mathrm{cr}$

Figure 6 . Reaction rate vs $\mathrm{FeO}$ content of slag for reduction by graphite and coke spheres.

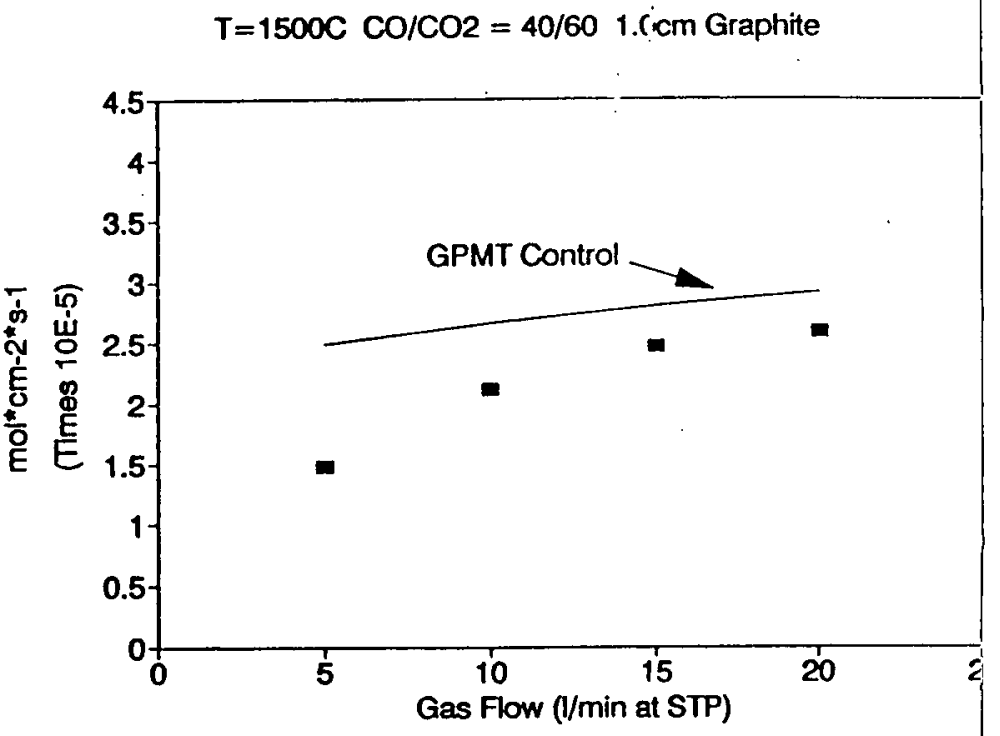

Figure 8. Carbon loss flux. 
3. Measurements of gas evolution in $\mathrm{CO}-\mathrm{CO}_{2}$ gas mixtures reflecting smelting indicate the $\mathrm{Fe}_{2} \mathrm{O}_{3}$ is transferred to $\mathrm{Fe}_{3} \mathrm{O}_{4}$ while going into solution.

4. A heat transfer model was developed to predict solution rates in smelting. At $1600^{\circ} \mathrm{C}$ in a bath smelting system, dissolution of $\mathrm{FeO}$ or $\mathrm{Fe}_{2} \mathrm{O}_{3}$ will take less than 10 seconds. In the process at projected production rates, less than $1 \%$ of the slag will be undissolved pellets.

\section{Rate of Reaction of Fe-C Drops in slag}

This work is completed and a report submitted to AISI. The results were reported in the 1990 report and are being used in a reduction model discussed in the section on modeling.

\section{Reduction of Feo in smelting slags by Solid Carbon}

One of the major reactions responsible for reduction is between carbon as coal char and Feo dissolved in slag. The rate has been measured for rods, disks, and spheres of graphite, coke, and coal char; typical results are shown in Figure 6 . The rate is similar for the different forms of carbon. A reaction model has been developed including liquid phase mass transfer and chemical kinetics. The model indicates that the mass transfer coefficient increases as the gas evolution rate increases, as shown in Figure 7. That means the reaction is autocatalytic, in that the reaction itself accelerates the rate.

Rate of Reduction of Fe-C Drops and Coal Char in Post Combustion Gases

The reactions of carbon dissolved in liquid iron or as coal char with the postcombusted gases can lead to "depostcombustion," resulting in lower energy efficiency by the reactions: 


$$
\begin{gathered}
\mathrm{C}+\mathrm{CO}_{2}=2 \mathrm{CO} \\
\mathrm{C}+\mathrm{H}_{2} \mathrm{O}=\mathrm{CO}+\mathrm{H}_{2}
\end{gathered}
$$

The rate of the upper reaction has been measured using a thermogravimetric technique. Experiments have been conducted to date with graphite and coke. Experiments are underway using coal char. Typical results are shown in Figure 8 along with the rate for gas phase mass transfer control (GPMT). It can be concluded that the rate of reaction is fast and controlled by gas phase mass transfer. Similar experiments are planned using $\mathrm{H}_{2} \mathrm{O}$.

The reaction of Fe-C melts with $\mathrm{H}_{2} \mathrm{O}$ and $\mathrm{CO}_{2}$ will be measured using specially built experimental equipment. Fe-C melts will be inductively melted and the reaction with gas mixtures containing $\mathrm{CO}_{2}$ or $\mathrm{H}_{2} \mathrm{O}$ will be determined by measuring the gas composition with an inline mass spectrometer.

\section{Model of Overall smelting}

The results of the laboratory and theoretical studies are being combined with pilot plant data to develop an overall model for the process. For example, the number and size of metal drops in the slag, as determined from samples from the pilot plant trials, will be combined with the rate constants determined from laboratory studies to determine the amount of iron produced from this reaction. The model will be comprehensive and consider solution of pellets, gas evolution from the pellets, all the reduction reactions, the depostcombustion reactions, and coal devolatilization. The model will consist of kinetic and mass balance equations.

To date, a simple reduction model has been developed. The model considers the reduction due to char $\left(R_{C}\right)$, metal drops $\left(R_{D}\right)$, and the metal surface $\left(R_{S}\right)$. 


$$
\mathbf{R}=\mathbf{R}_{\mathbf{C}}+\mathbf{R}_{\mathbf{D}}+\mathbf{R}_{\mathbf{s}}
$$

The model used kinetic data from CMU and published results and predicted the rate of production within $10 \%$. $R_{s}$ represents less than $10 \%$ while $R_{D}$ and $R_{S}$ are about equal.

Also, the theoretical production rate for a generic $100 \mathrm{~m}^{3}$ demonstration size smelter has been estimated in terms of the useful volume for foaming and reduction control. The volume of foam $\left(V_{f}\right)$ is related to the gas flow rate (Q).

$$
\mathrm{V}_{\mathrm{f}}=\Sigma \mathrm{Q}
$$

and the rate of reduction depends on the volume of slag.

$$
\mathrm{R}=\mathbf{k} \mathrm{V}_{\mathrm{s}}
$$

The useful volume of the vessel (V) is given by:

$$
\mathrm{V}=\mathrm{V}_{\mathrm{f}}+\mathrm{V}_{\mathrm{s}}+\mathrm{V}_{\mathrm{M}}
$$

where $V_{M}$ is the volume of the metal. Allowing $65 \mathrm{~m}^{3}$ of the vessel to be utilized, the foam volume and available volume are plotted in Figure 9 for 1 and 3 atmospheres as a function of production rate. The maximum rate is determined by the intersection of the lines and is 40 and 62 tonnes/hr at one and three atmospheres, respectively, for the AISI rate. This converts to production intensities of 9.6 and 15 tonnes/ $\mathrm{m}^{3}$ day, respectively, for the $100 \mathrm{~m}^{3}$ vessel.

TASR 1 - PHYSICAL CHEMISTRY RTUDIES - MIT

The research program broadly consisted of investigating several smelting reactions that may take place between various types of particles and liquid phases (iron and slag) in the bath smelter. Important materials that are of interest to the in-bath smelting 


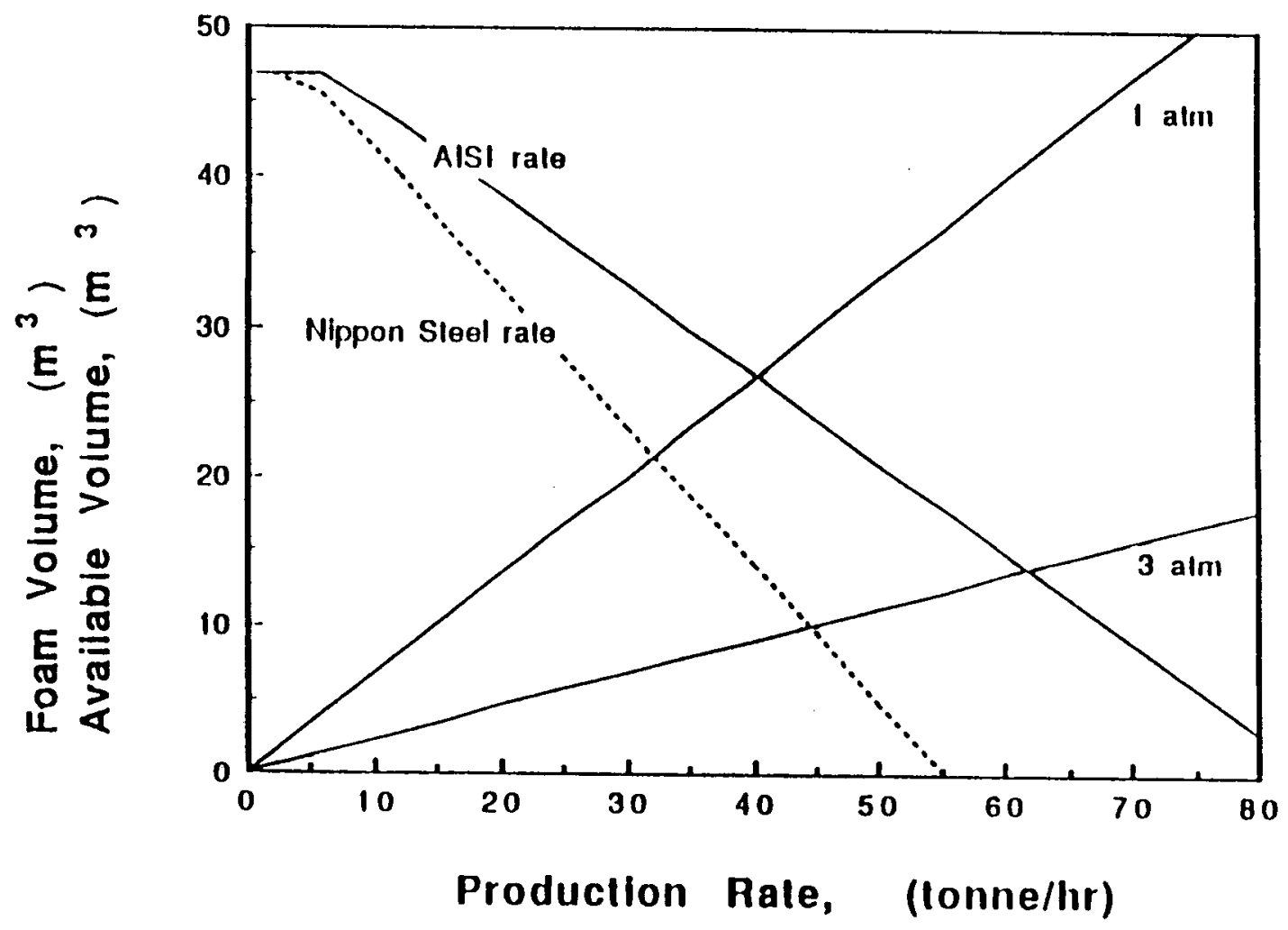

Figure 9. Produclion rale for a $100 \mathrm{~m}^{3}$ reaclor using 60-65 m . 
process are partially reduced iron ore pellets or fines; coarse lump coals, coal char, and coke; and Fe-C droplets. The rates of interaction of these materials with liquid Fe-C alloys and slags may depend on their size, shape, and composition. The purpose of this project was to develop a fundamental understanding of the interactions of several of these materials with liquid $\mathrm{Fe}-\mathrm{C}$ alloys and with liquid $\mathrm{CaO}-\mathrm{SiO}_{2}-\mathrm{Al}_{2} \mathrm{O}_{3}$ slags by conducting both experimental investigations and mathematical model calculations.

\section{Heating and Melting of Oxide Particles}

The focus of this investigation was to determine the rate of dissolution and to examine the physical changes that a cold oxide pellet undergoes when immersed in a liquid slag. A numerical model previously developed at MIT was used to estimate the rate of heating and melting of pure hematite, wustite, commercial ore, and DRI pellets. The model predictions were compared with the experimentally determined values of rates of melting. The model was employed to predict temperatures within the pellet, particularly at the center and surface of the pellet; the formation and melting of a solid slag layer on the surface of the pellet; and melting of the pellet.

The model predictions were validated using experimentally determined values for complete melting of wustite and hematite pellets. The experiments were carried out at three different temperatures, $1450^{\circ}, 1500^{\circ}$, and $1550^{\circ} \mathrm{C}$, employing a single wustite or hematite pellet of $2-6 \mathrm{~g}$. Several $\mathrm{x}$-ray images obtained during interaction of a pellet with liquid slag were used to determine the time for complete dissolution of the pellet, $t_{d}$, into the slag. The physical, changes that a pellet undergoes were studied by examining the samples of pellets which were immersed into the liquid slag and withduawn after a known time. Several experiments were also carried out to actually measure the temperature profiles of a pellet. 
The values of $t_{d}$ for both wustite and hematite increased with increasing pellet size and decreasing bath temperature (values of $t_{d}$ determined in the present investigation varied between 14 and $70 \mathrm{~s}$ for wustite and 35 and $105 \mathrm{~s}$ for hematite). In general, the value of $t_{d}$ for a hematite pellet at a given temperature was more than that for a wustite pellet of equal weight. Examination of microstructures of partially interacted pellets revealed that the mechanism of melting and dissolution of wustite was different from that of hematite. It was clear, from the comparison of the experimentally obtained temperature profile of a heating pellet with that predicted using the numerical model, that the actual initial rates of heating were less than those predicted theoretically. However, the experimentally determined values of $t_{d}$ were in good agreement with those predicted using both numerical and simple shrinking-core models (Figure 10).

\section{Reactions of coals and Coal Chars with Fe-C Melts}

Flash pyrolysis experiments were carried out with samples of anthracite and the low, medium, and high volatile bituminous coals that are being used in the AISI test furnace at temperatures between 1350 to $1600^{\circ} \mathrm{C}$. The results are compared with those obtained from proximate analysis. The size of the samples was between 3 and $6 \mathrm{~mm}$. The extent of devolatilization of different types of coals was determined by measuring the sample weight loss or composition and flow rate of the offgases. The offgases contained essentially $\mathrm{H}_{2}, \mathrm{H}_{2} \mathrm{O}, \mathrm{CO}, \mathrm{CO}_{2}$, and $\mathrm{CH}_{4}$, and the ratio of $\mathrm{H}_{2} / \mathrm{CO}$ was higher for low volatile coals as compared to that for a high volatile coal and the average molecular weight of the offgases increased with decreasing rank of coal.

Several experiments were carried out to determine the rates of dissolution of spectroscopic graphite, coke, and coal chars into Fe-C melts by immersing a cylindrical sample at $1450-1600^{\circ} \mathrm{C}$. Times of Immersion ranged from 10 to $210 \mathrm{~s}$ and the values of dissolution coefficient, $k_{1}$, were estimated based on the measured 




Figure 10. Comparison of experimentally determined time for complete melting of wustite pellets with those estimated using MIT numerical and shrinking-core models at $1500^{\circ} \mathrm{C}$.

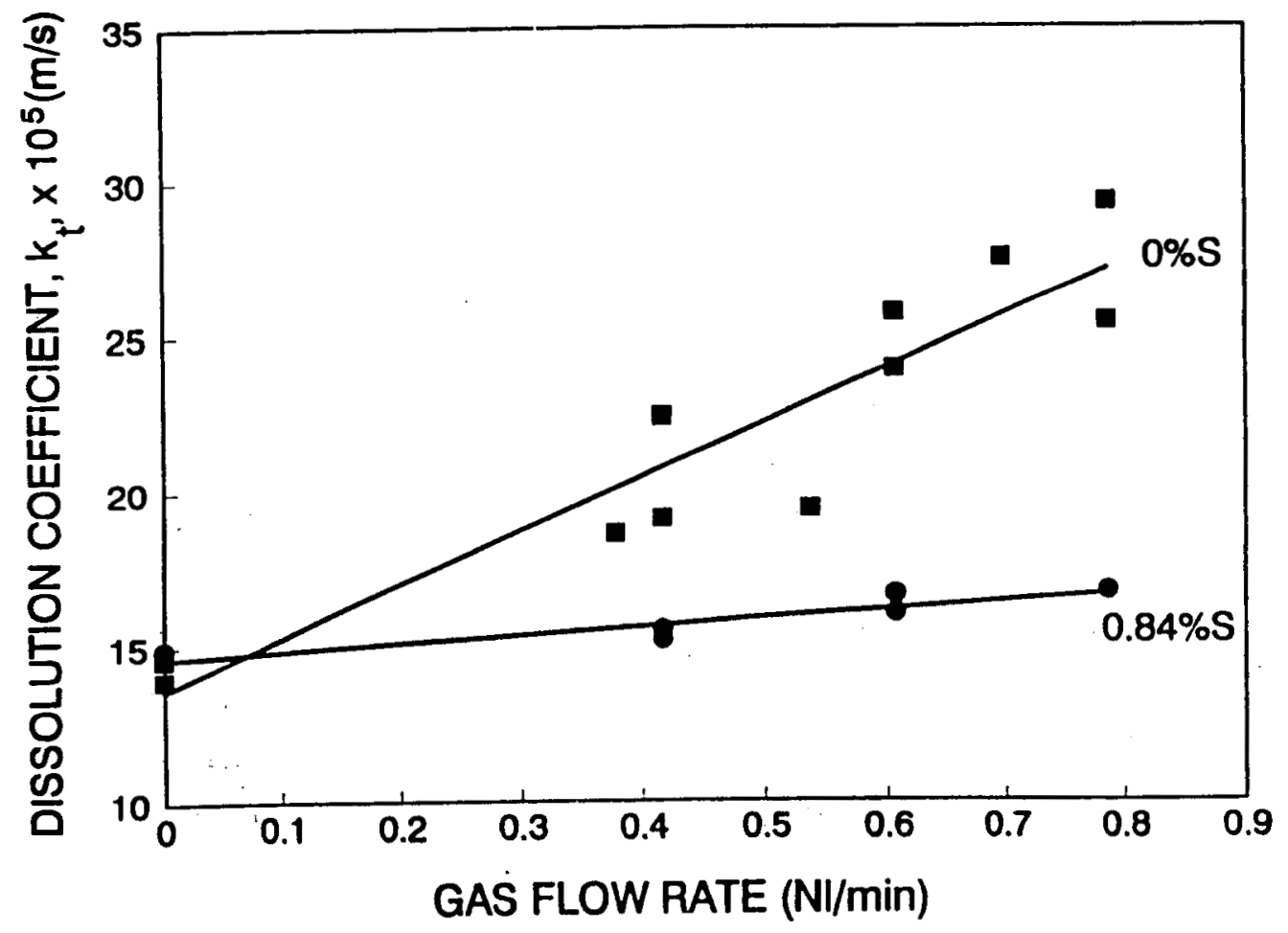

Figure 11. Effect of sulfur on dissolution rates of spectroscopic graphite in low carbon iron alloys at $1450^{\circ} \mathrm{C}$. 
weight loss of the immersed cylindrical samples. The values of $k_{1}$ were found to be in the range $8.3 \times 10^{-5}-20.6 \times 10^{-5} \mathrm{~m} / \mathrm{s}$ for graphite and $1.8 \times 10^{-5}-28.1 \times 10^{-5} \mathrm{~m} / \mathrm{s}$ for industrial coke. The values of $k_{l}$ were functions of bath temperature, bath carbon concentration, and sample immersion time. The following correlation was obtained for spectroscopic graphite

$$
k_{t}=0.19\left[\begin{array}{llll}
g & \Delta & \rho & \rho_{\mathrm{s}} / \mu
\end{array}\right]^{1 / 3}\left(D_{\mathrm{c}}\right)^{2 / 3}
$$

where $g$ is acceleration due to gravity, $\mu$ is the viscosity of the melt, $D_{c}$ is the diffusion coefficient of carbon in the liquid Fe-C melt, $\rho_{s}$ is the density of carbon saturated iron melt, and $\Delta \rho$, buoyancy factor, is defined as $\left(\rho_{s}-\rho\right) / \rho$, where $\rho$ is the iron melt density.

Surface-active impurities like sulfur in the melt reduce the rate of dissolution of carbon in Fe-C melt. A comparison of dissolution coefficients of graphite obtained with and without sulfur in the melt is shown in Figure 11. As expected, the sulfur in the melt decreased the rate of dissolution of the samples.

The extent of devolatilization and dissolution of three different types of coal particles (low, medium, and high volatile) in iron carbon alloys were also examined by conducting several experiments. The particles were either injected into the bath or placed on the melt surface at $1550^{\circ} \mathrm{C}$. The amount of carbon recovered was estimated by analyzing the melt samples for carbon and by measuring offgas composition and mass flow rate. The results of these experiments were compared with those obtained using the immersed cylindrical samples. The recovery of carbon in the experiments using immersed samples of both graphite and coke was nearly complete. On the other hand, the carbon recovery was only about 778 when medium volatile coals were dropped onto the melt surface and only 598 when they were injected. 


\section{Interaction of Feo with Fe-C Melts}

Reduction rates of iron oxides by Fe-c melts were calculated employing the experimentally measured $c o(g)$ volume flow rates (or increase in pressure of the closed reactor). It was shown, based on the experimental data obtained using four different crucibles having cross-sectional areas of $14,23,39$, and $102 \mathrm{~cm}^{2}$ at temperatures ranging from $1450^{\circ} \mathrm{C}$ to $1650^{\circ} \mathrm{C}$, that the time for complete reduction, $t_{R}$, of an oxide pellet can be related to the initial moles of oxygen in the pellet, $M_{0}$, and the relationship is given by

$$
\ln t_{\mathrm{R}}=-\ln (1-n) k+(1-n) \ln \left(M_{\mathrm{o}} / A_{\mathrm{m}}\right)
$$

where $A_{m}$ is melt cross-sectional area, $n$ and $k$ are the order and the apparent rate constant for the overall reaction, respectively. The values of $n$ and $k$ were found to be on the order of $0.2-0.6$ and 0.002 - 0.07, respectively. The values of both $n$ and $k$ increased with increasing bath temperature, but the value of $k$ decreased with increasing the bath cross-sectional area.

Several experiments were also conducted to determine the rates of reduction of iron oxides as functions of volume of $\mathrm{CaO}-\mathrm{SiO}_{2}-\mathrm{Al}_{2} \mathrm{O}_{3}$ slags present on an iron-carbon bath surface at $1450-1550^{\circ} \mathrm{C}$. The effects of pellet size, pellet type (wustite or hematite), bath temperature, crucible diameter, and slag volume on the reduction rates were examined. : The experimentally determined time for complete reduction of a $3 \mathrm{~g}$ hematite pellet by an iron-carbon(sat) bath having $50 \mathrm{~g}$ slag: on its surface at $1450^{\circ} \mathrm{C}$ was about $38 \mathrm{~min}$ (whereas it took only $24 \mathrm{~s}$ for a $3 \mathrm{~g}$ hematite pellet to react with a bath having no slag). As is evident from Figure 12, the reduction rate of a pure oxide pellet was a linear function of time in the initial stages (up to about $40 \%$ of the original pellet was reduced), and in the later stages the relationship was nonlinear. 


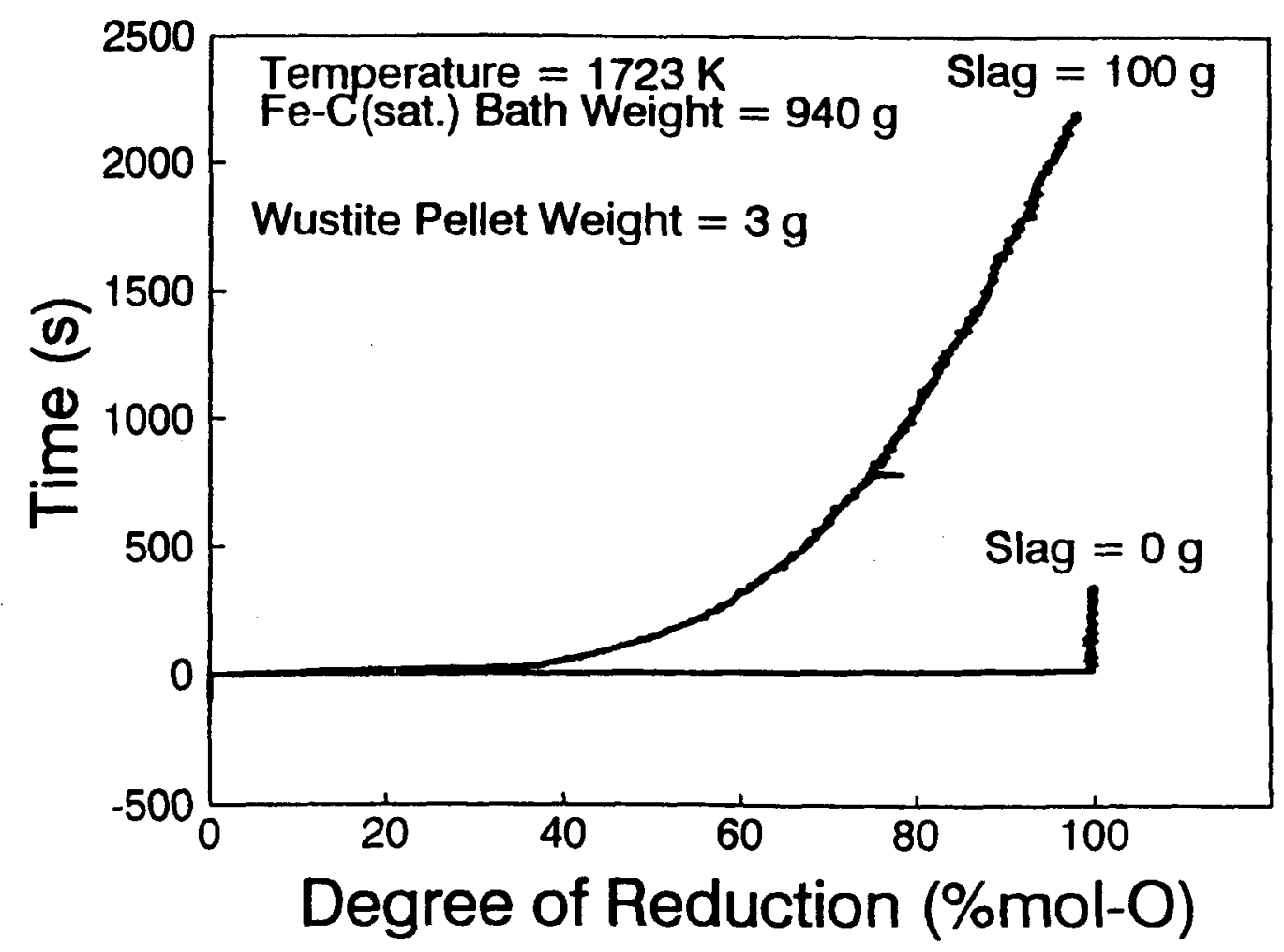

Figure 12. A plot of degree of reduction as a function of time for a wustite pellet reacting with a iron-carbon melt having $50 \mathrm{~g}$ slag on its surface at $1450^{\circ} \mathrm{C}$.

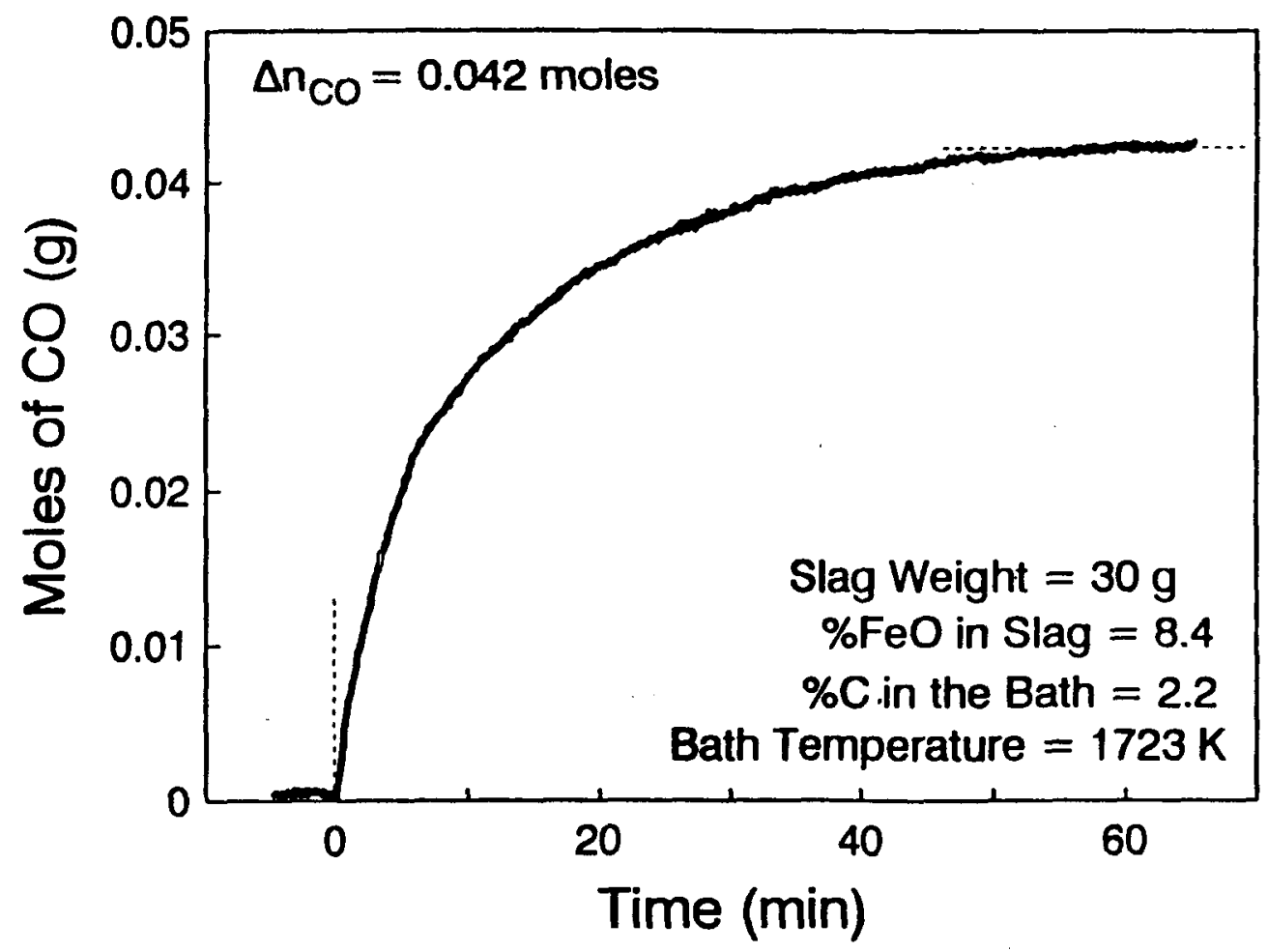

Figure 13. Evolution of $\mathrm{CO}(\mathrm{g})$ as a function of time during reaction of $30 \mathrm{~g}$ slag $(\mathrm{CaO}: 42.5 \%$; $\left.\mathrm{SiO}_{2}: 38.2 \% ; \mathrm{Al}_{2} \mathrm{O}_{3}: 11 \% ; \mathrm{FeO}: 8.4 \%\right)$ with $\mathrm{Fe}-\mathrm{C}(2.2 \%)$ melt. 
It was also established that the rates decreased with increasing slag volume on the metal bath surface and decreasing bath temperature.

\section{Reactions of $\mathrm{Fe}-\mathrm{C}$ Melts with slags}

Reduction rates of iron oxides dissolved in liquid CaO- $\mathrm{SiO}_{2}-\mathrm{Al}_{2} \mathrm{O}_{3}$ slags by $\mathrm{Fe}-\mathrm{C}$ droplets were determined experimentally at temperatures in the range $1325-1550^{\circ} \mathrm{C}$. The rates were estimated using the experimentally measured rates of $\mathrm{CO}(\mathrm{g})$ evolution. The reduction rate, $r$, was defined as the rate of moles of oxygen lost in the first minute per unit surface area of a reacting $\mathrm{Fe}-\mathrm{C}$ droplet (initial rate of reduction). The surface areas of the droplets were based on the average sizes of the droplets which were determined using $\mathrm{X}$-ray images obtained about $30 \mathrm{~s}$ after the droplet was introduced into the slag.

The effects of $8 \mathrm{FeO}$ in slags $(5.5-18 \%)$, temperature (1325 $1550^{\circ} \mathrm{C}$ ), droplet size ( 1 and $2 \mathrm{~g}$ ), initial droplet surface area (single droplet versus five droplets), carbon content of $\mathrm{Fe}-\mathrm{C}$ droplet (1.75\% - C(sat)), sulfur in Fe-C droplet $(0,0.38$, and $0.558 \mathrm{~S})$, and phosphorus in slag $\left(0,1.65\right.$, and $\left.3.35 \% \mathrm{P}_{2} \mathrm{O}_{5}\right)$ on reduction rates were examined. It was also established that the order of reactions obtained employing the initial rates of reduction of $\mathrm{FeO}$ in slags by $\mathrm{Fe}-\mathrm{C}$ (sat) droplets was zero with respect to carbon in the droplet and was first order with respect to $\mathrm{FeO}$ in the slag. The reduction rates increased with increasing slag temperature, and the temperature coefficients of the overall reduction reaction were $221 \mathrm{~kJ} / \mathrm{mol}-\mathrm{o}$ and $237 \mathrm{~kJ} / \mathrm{mol}-\mathrm{o}$ for $8.11 \%$ and $13.12 \%$ Feo slags, respectively.

An attempt was made to examine the effect of carbon on the reduction rates of $\mathrm{Feo}$ dissolved in slag by low carbon $\mathrm{Fe}-\mathrm{C}$ melts. Several experiments were conducted at $1450^{\circ} \mathrm{C}$ using two types of melts $\left(27 \mathrm{~cm}^{2}\right.$ in cross-sectional area) having 1.3 and $2.2 \% \mathrm{C}$. The experiments consisted of dropping a known amount of solid or molten 
slag ( $\mathrm{CaO}: 42.58 ; \mathrm{SiO}_{2}: 38.28 ; \mathrm{Al}_{2} \mathrm{O}_{3}: 118 ; \mathrm{FeO}: 8.48$ ) onto a flat $400 \mathrm{~g}$ Fe-C melt and monitoring the rate of $\mathrm{CO}(\mathrm{g})$ evolved from the reactions. The amount of slag used in an experiment was in the range of $10-90 \mathrm{~g}$. A typical trace of moles of $\mathrm{co}(\mathrm{g})$ evolved versus time is given in Figure 13. As can be seen from Figure 13, a significant amount of $\mathrm{CO}(\mathrm{g})$ evolved in these experiments, and almost all of the Feo present in the slags was reduced by $\underline{c}$ in $\mathrm{Fe}-\mathrm{C}$ melts. Flash X-ray images obtained during the reduction reactions suggested that the reactions proceeded with formation of a large amount of foam as soon as the slag was dropped onto the Fe-C melt. It was also evident from the $X$-ray images that a gas film formed after several minutes on the Fe-C melt surface and was separating the Fe-C melt from the slag phase. Moreover, it was established, based on the initial reduction rates, that the interaction between Fe-C melt and slag was primarily governed by the concentration of Feo remaining in the slag and was virtually independent of $q \underline{c}$ in Fe-C melt or the weight of the slag. The maximum amount of foam generated during the reduction reactions was found to increase linearly with the weight of the slag.

\section{TASK 2 - CONTINUOUS REFINING}

Project completed and reported in 1990 report.

\section{TASR 3 - BMELTER OPERATION}

\section{Introduction}

The unique feature contributing to the success of the smelter is the creation of a foamy slag above the hot metal in which most of the energy is generated and most of the reduction takes place. The foamy slag owes its existence to the injection of oxygen that reacts with some of the coal to generate the necessary heat and co for the foamy slag and the additional generation of co from the 
reaction of carbon both from the coal and in the metal droplets in the foam with the iron oxide to reduce it to iron and help maintain the foam. The key to success in maintaining the foam is careful control of its composition by precise control of the rates, sites, and compositions of the raw material feeds, in particular the ore, coal, and oxygen.

Because the offgas from the smelter contains appreciable energy, the efficiency of the process can be increased substantially by using this energy to preheat and prereduce the ore. In the integrated process, taconite pellets will be preheated and prereduced to wustite, Feo, by use of the offgas. Consequently, most of the trials with the vertical vessel were conducted with wustite that had been prereduced by HYLSA in a pilot plant in Monterrey, Mexico, and shipped to the pilot smelter in Universal, Pennsylvania.

The vessel for the initial pilot plant trials has been called a vertical vessel. It is similar in shape to a small BOP type vessel. Consideration has also been given to a "horizontal" vessel, that is, a vessel with an oval or rectangular cross section in plan view, as opposed to one with a cylindrical cross section, but the vertical vessel was selected for the first phase. (Installation of a horizontal vessel is nearing completion and will soon be in trial operation, first as a single-zone process and subsequently as a two-zone process with different operating conditions on opposite sides of a central barrier.) Figure 14 shows a cross section of the vertical vessel and its refractory lining. Figure 15 is a schematic of the vessel in operation, showing the hot metal at the bottom, a transition zone, a foamy slag region penetrated in part by oxygen from the lance, and the freeboard. Figure 16 is a flowsheet of the integrated process using a high-volatility coal.

The vertical vessel was operated for 49 trials over a period of fourteen months to determine such key process operating conditions 




FIGURE 15 


\section{Smelter Flowsheet}




as rate of ore reduction, degree of postcombustion achieved, heat transfer efficiency to slag and hot metal, and utilization of the fixed carbon and volatile matter in the coal, as well as stability and ease of operation.

The rate of ore reduction is generally calculated in terms of tons per hour per square meter of bath surface and sometimes converted to a useful figure of merit of production intensity in tons per day per cubic meter of vessel.

Degree of postcombustion, PCD, is equal to

$$
\frac{\mathrm{CO}_{2}+\mathrm{H}_{2} \mathrm{O}}{\mathrm{CO}+\mathrm{CO}_{2}+\mathrm{H}_{2}+\mathrm{H}_{2} \mathrm{O}} \times 100
$$

and is an inverse measure of the energy remaining in the offgas.

The heat transfer efficiency, HTE, is equal to

$$
\left(1-\frac{\text { sensible superheat energy in the exhaust gas }}{\text { total energy calculated for post combustion }}\right) \times 100
$$

where the sensible superheat is defined as the sensible heat in the exhaust gas arising from any temperature greater than hot-metal temperature. It is a measure of the utilization of the energy from combustion of the coal in the smelting process. Fixed carbon is the carbon in the non-volatile portion of the coal, and volatile matter is that matter released when coal is pyrolyzed.

\section{Variables studied and Process Measurements Made}

Among the variables studied in the 49 trials were seven types of coal, including coke breeze and anthracite; three sources of iron; two fluxes and various slag basicities; oxygen lance position and 
lance design; side injection of oxygen and side injection of coal; char volume in the slag; different levels of bottom stirring with nitrogen; and twelve different refractory brick.

The data logging system monitors 525 sensors, of which about $25 \%$ are analog, every 4 seconds and retains these in revolving storage during operation for four hours. One-minute averages are calculated and retained in a permanent database. In addition, input raw material compositions and output material compositions analyzed subsequently are calculated as input and output rates and added to the database for a total of about 7000 data points in the database for each minute of operation.

All raw material feed rates and gas flows, both top fed and injected, are monitored. Two mass spectrometer gas analyzers provide continuous analysis of the freeboard gas and the stack gas. Thermocouples measure temperatures of refractories, offgas in the vessel and duct, and water-cooling circuits continuously. Hot metal and slag temperatures are measured intermittently by a sensor lance, as are foam height and hot metal level. The sensor lance is also used to take hot metal and foamy slag samples during oxygen blowing.

Measurements of hot metal, slag, and raw material compositions are made on site by $x$-ray fluorescence spectroscopy, and carbon and sulfur are determined on site by Leco combustion analyzers. Additional composition determinations, such as for coals, are obtained from the USS Technical center, as needed.

Relative and cumulative dust loading of $\mathrm{Fe}, \mathrm{FeO}, \mathrm{C}$, and $\mathrm{S}$ is determined from the scrubber sludge at the end of a trial, and relative and absolute loadings are determined by sampling the scrubber stream at least once during each run segment. The results are in accord. 


\section{Process Control strategies and system}

The process is controlled primarily by controlling the feed rate of the raw materials: ore pellets, coal, oxygen, and flux. Blowing practice that involves lance position, hard or soft blow, and primary to secondary oxygen ratio, and nitrogen stirring energy have lesser but still significant effects and must be optimized for maximum productivity.

The ore addition rate is established by the aim production rate. The coal rate is governed by the ore addition rate and in turn establishes the oxygen rate. The coal rate and oxygen rates are modified according to the need to raise or lower the operating temperature or to raise or lower the char volume. The char volume must be controlled to achieve a stable foamy slag, and the slag basicity, which also affects the stability of the foam, must be controlled by flux additions.

The degree of postcombustion is largely controlled by lance position and by the primary to secondary oxygen ratio for a given lance design. The volatile matter bypass is controlled largely by the choice of coal, but for a given coal the bypass is also controlled by the ratio of top-fed coal to side-injected coal and by the oxygen blowing practice. The dust losses to the stack are controlled to a large extent by the oxygen blowing practice and its effect on the foam turbulence and secondarily by the raw material particle size and introduction or injection practices.

The process control system is composed of an IBM 9370 Model 90 computer acting as a level 2 controller for five Allen-Bradley level 1 Programmable Logic Controllers (PLC). PLC-1 is used for supervisory and safety functions, PLC-2 for gas cooling and cleaning functions, PLC-3 for bulk material handling functions, PLC-4 for pneumatic injection functions, and PLC-5 for gas flow systems. The PLCs interface and communicate with a large variety of analog and digital instrumentation. The level 1 communication occurs via a data highway developed by Allen-Bradley for 
intercommunication among PLCs. An IBM PC is also connected to the data highway and is provided with special software to allow programming of the PLCs.

Specially developed device-driver software was installed on the level 2 system to provide for communication by the IBM 9370 with the five PLCs. The IBM 9370 is functionally a node on the data highway.

Additional functions have been added to the control system. Software has been installed to move files from the IBM 9370 database to the engineers' workstations for off-line data analysis. The software interfaces to PC spreadsheet programs, as well as to database files for PC-based statistical software. Figure 17 shows the entire hierarchical control system.

The process operates on the basis of set points and aims established by the operator and feedback from sensors to control systems to achieve these set points. A control system based on an integrated process model awaits completion of the integrated model.

\section{Operating Procedures}

In order to maintain a stable operation with consistency from trial to trial, standard operating procedures were developed for vessel operation. These procedures helped to maximize the information obtained from each trial and assure, as closely as possible, that all trials started from the same operating conditions and parameters.

The pre-trial checklist assured that all systems were checked and verified before the trial started and helped to guarantee that the systems would perform to specifications once the trial was started. The operating procedures were designed to bring the hot metal and slag quantity and temperature to the same point at the start of each trial. The sampling procedures assured that all the necessary samples and data were collected. The operating plans for each 


\section{AISI-DOE Direct Steelmaking}

\section{Hardware Diagram}

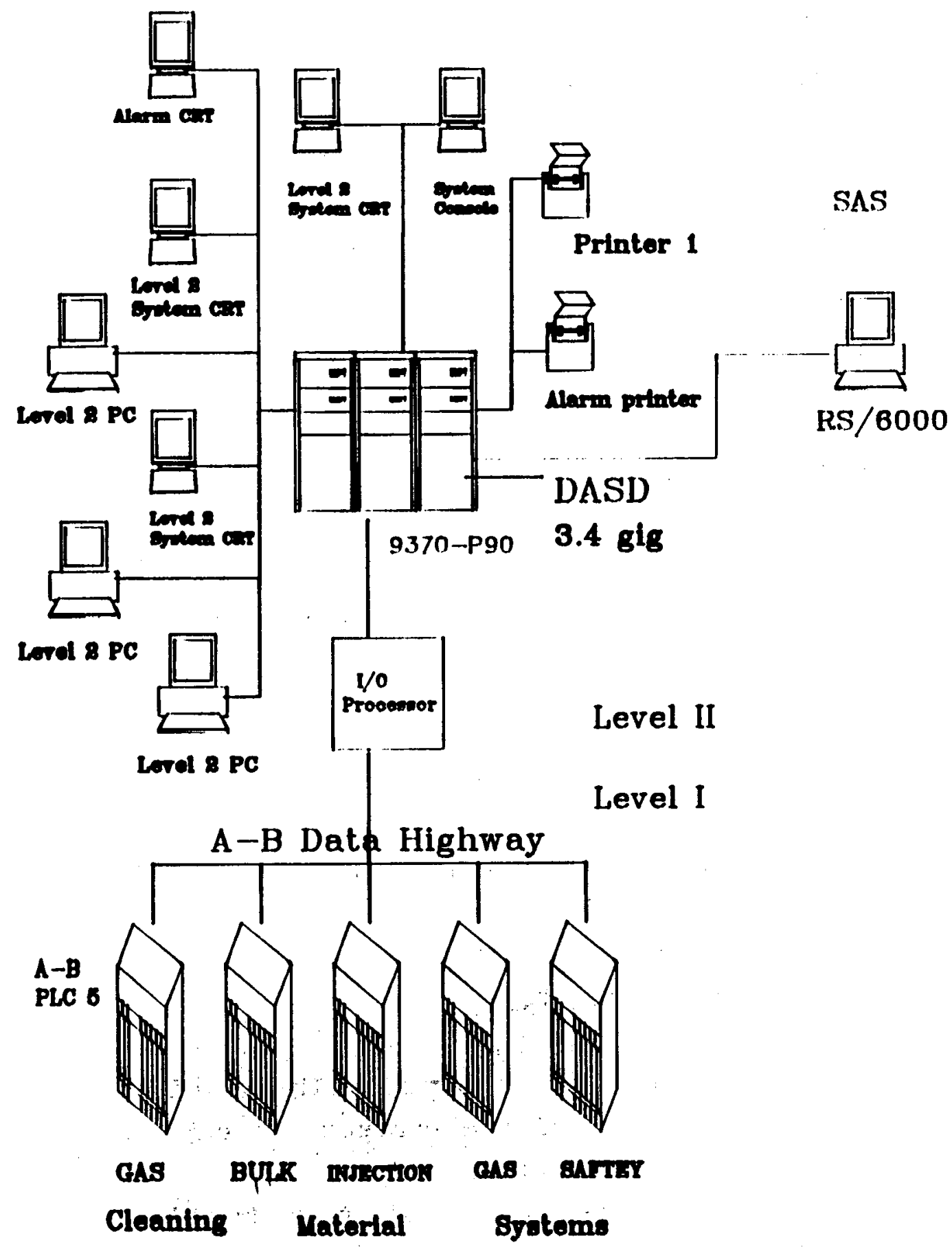

AISI-DOE Direct Steelmaking

FIGURE 17 
trial were developed for that trial, depending on the variables or parameters that were to be studied. standard procedures for controlling hot metal temperature and char (foam control) were developed and followed. Shutdown procedures allowed for a safe completion of the trial with consideration for setting the plant up for the next trial.

In most cases, detailed procedures were written and then broken down to a checklist format that was used before and during the trials. The procedures were used for training, and the checklist was used for the trial. The procedures were developed and modified to operate the plant in the safest possible manner. They also assured that the maximum amount of information from each trial was obtained and that there would be minimal equipment failures during a trial. The operating philosophy behind the procedures was to obtain the most information from a trial, but if there was a major problem, stop the trial and minimize the damage. The goal was to obtain data at steady-state operating conditions. The goal was generally achieved each week; the remainder of the week was used for recovery and for preparation for the next week's trial.

\section{Startup and Shutdown}

Startup and shutdown procedures have also been developed and documented. They provide a detailed checkout of all systems in the plant and the sequence and timing for each startup and shutdown operation.

\section{Description of a Typical Trial}

A typical trial begins with a visual walk-around safety inspection and a pretrial checkout of all systems the day before the trial. Burners are used to preheat the vessel, ladle, casting boxes, and the slag spout and slag box. About midnight, melting of the initial hot-metal charge in the 15-ton induction furnace is begun. When the hot metal is at temperature, the preheater is removed and the initial slag charge is added. The hot metal is charged next, 
and various platforms and shields are put in place to facilitate operation and turndown sampling. The lances are lowered, samples and measurements are taken, and a "run segment" begins with start of the oxygen blow.

The segments are typically separated by vessel turndowns for sampling and adjustments, but a run segment is officially defined as the time from start to stop of the oxygen blow, usually about 30 minutes. At turndown, slag and metal temperatures are measured and metal, slag, and char are sampled. slag is poured off if appropriate.

The first three segments (approximately 1-1/2 to 2 hours) are used to melt the initial slag charge and to bring the vessel to the designated stable condition. The coal and the fluxed wustite pellets and any additional fluxes are added from the top, falling into the vessel by gravity. oxygen is blown through a dual-pressure-system lance with a higher pressure for the jet exiting from the bottom (primary) and lower for the jets exiting from the side (secondary) of the lance. The hot metal is stirred by bottom-blown nitrogen.

The remaining segments are for the planned experimental conditions and may last for 30 minutes or as much as two hours at a given set of conditions. When the hot metal reaches the casting level, the taphole is opened and casting is continuous.

Temperatures, samples, and foam-height measurements are taken every 15 to 30 minutes, and vessel gas analysis takes place when the sensor lance is not in use.

Figure 18 is a typical operating plan, in this case for trial number 40. The objective of this trial was to maintain high degrees of postcombustion by either adjusting the lance height (condition 1 ) or by adjusting the ratio of primary to secondary 
OPE RATING PLAN FŌ TRIAL $4 \overline{0}$

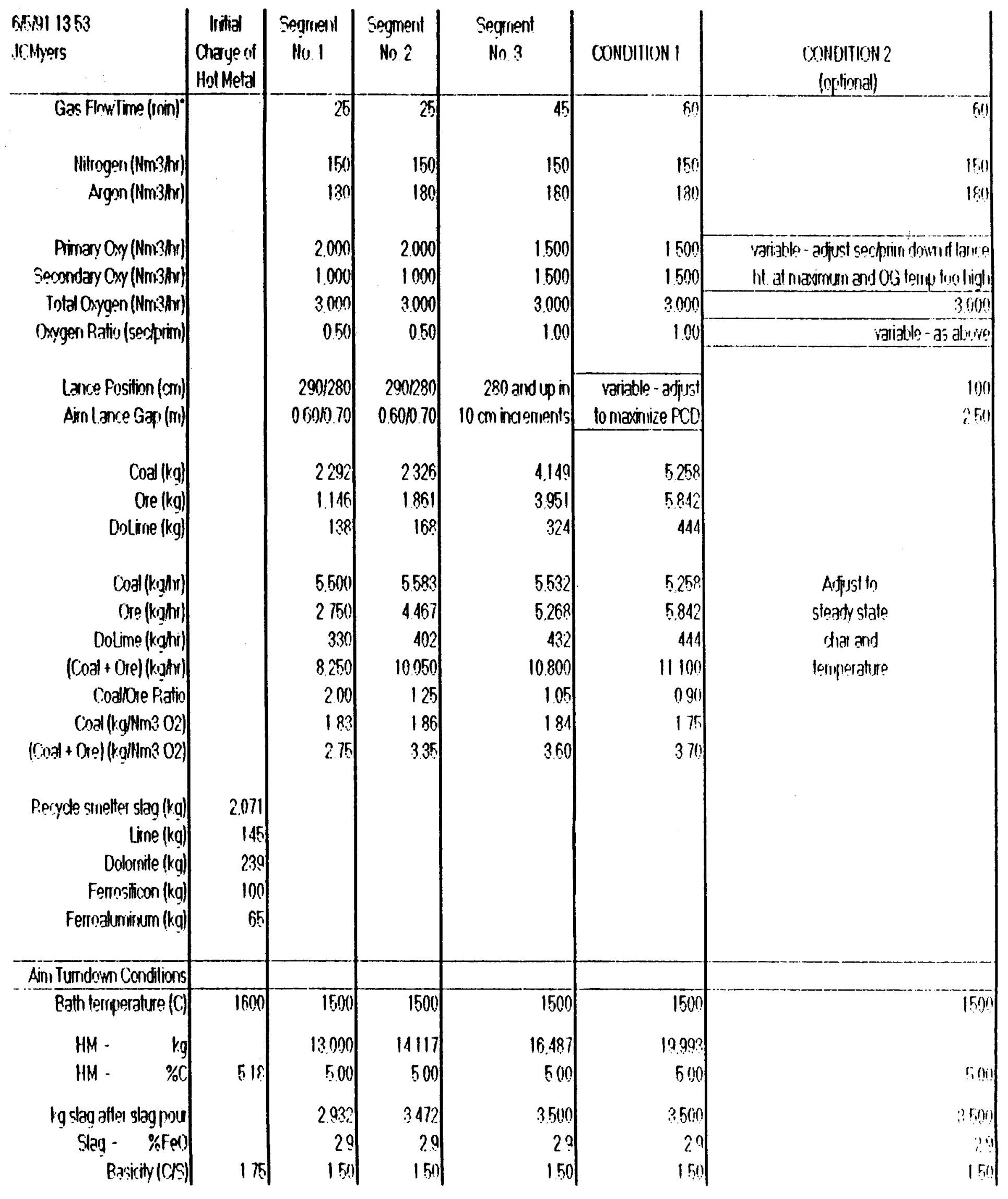

FIGURE 18 
oxygen in the jet (condition 2). If stable baseline conditions are not maintained for a given segment, that segment is repeated until stable conditions are achieved.

To control the metal temperature during a segment, the total amount of coal and ore are varied and the appropriate amount of oxygen is injected. For example, too high a temperature calls for an increase in the total amount of coal and ore. Too little char, which leads to excessive slag foaming, calls for an increase in the ratio of coal to ore but keeping the total constant to maintain a constant temperature. Offgas temperature must be controlled to remain under $1650 \mathrm{C}$ to minimize refractory loss. This is best controlled by controlling the degree of postcombustion, which is controlled by lance-height adjustments.

At the end of a trial, perhaps in the early evening, the slag is poured off into slag pots and the metal is tapped into the ladle and transferred to refractory lined boxes for solidification and reuse for the next trial.

The process is quite forgiving in that recovery from upsets and transition to rather different operating conditions can be readily accomplished. In one case involving malfunction of the coal injection system, the vessel was put on hold for almost three hours with only the nitrogen stirring tuyeres activated. When the injection system was restored, the vessel was brought back to the desired steady-state operation within 30 minutes.

\section{Results of Operations}

\section{Energy and Mass Balance}

Energy and mass balance models have been developed and applied to pilot plant data essentially independently by three organizations using their own systems for building the model. The CMU smelting model initially developed by Ito and Fruehan has been adapted by Myers and pratt to be more applicable to the pilot plant. 
Zhiyou Du of UCIG has developed a parametric model independently that has been applied to pilot plant data. Mannesmann Demag has adapted its generic ironmaking model to the AISI process and applied it to data generated at the pilot plant. The models are in excellent agreement with respect to energy requirements and energy balances as applied to the pilot plant data.

The mass balances are more difficult to close because assumptions and corrections must be made, especially to the gas composition and gas flow data. The variability of gas composition as determined by the gas analyzer for the gas sampled at the sensor lance indicates that the gas composition in the freeboard is quite sensitive to where the materials are reacting and the gas flows created by the volatile matter in the coal. Both this gas analysis and the stack gas analysis must be corrected for the water gas shift for the sampling temperature and the analyzing temperature. The assumption that equilibrium among the gas constituents exists, especially in the vessel freeboard, is also questionable.

Despite these concerns, there is general agreement that the process is understood and that the reaction rates measured can be converted and scaled up to those for a larger vessel with a process that recycles the fines that currently exit by way of the stack. Most of the operation was at a $40 \%$ degree of postcombustion and a heat transfer efficiency of 85 to $90 \%$.

Table 1 provides fuel rate averages by coal type for a coke and coal combination, an anthracite, Buchanan and Amonate (two medium-vol coals), and Rowland and EKO (two high-vol coals). steady-state coal rates are calculated to account for non-steady-state conditions with respect to temperature and char, which may each be increasing or decreasing during a run segment or a series of segments. The fuel rates are also corrected for the dust losses up the stack, as measured in the scrubber water. In an integrated plant, these dusts would be recycled. The data in 


\section{Pilot Plant Fuel Bate Averages by Coal Type}

$\begin{array}{rrrrrrr}\text { Coal Type Coal Injection } & \text { Anthracite } & \text { Buchanan } & \text { Amonate } & \text { Rowland } & \text { EKO } \\ \text { Volatile Matter (\%) } & 9.5 & 5.6 & 19.9 & 22.9 & 29.4 & 38.2\end{array}$

Raw Data Fuel Rate $(\mathrm{kg} / \mathrm{t})$

Fuel Rate Adjustment to Steady State $(\mathrm{kg} / \mathrm{t})$

$\stackrel{w}{w}$

Steady State Fuel Rate $(\mathrm{kg} / \mathrm{t})$

Fuel Rate Adjustment for Dust Recovery (kg/t)

Net Coal Rate $(\mathrm{kg} / \mathrm{t})$

Moisture (\%)

Fixed Carbon (\%)

Steady State Fixed C $(\mathrm{kg} / \mathrm{t})$

Steady State VM $(\mathrm{kg} / \mathrm{t})$

Net Fixed C $(\mathrm{kg} / \mathrm{t})$

Net VM $(\mathrm{kg} / \mathrm{t})$
1,014

30

984

$-35$

949

2.74

80.29

768

91

741

88

$$
1.226
$$

1.297

$-22$

1.270

1,482

1,828

$$
-42
$$

1.184

1.275

$-141$

$-161$

1.115

1.043

1.115

3.33

84.54

2.15

69.86

68.76

872

248

762

217

$\begin{array}{lll}848 & 904 & 930 \\ 282 & 415 & 662 \\ 742 & 696 & 733 \\ 247 & 320 & 522\end{array}$


the four rows at the bottom of the table have been calculated on a dry basis, correcting for the moisture in the coal. The raw data and the net fuel rates are summarized in the bar chart, Figure 19.

As the volatile matter of a coal increases, more volatile matter is bypassed or lost to the stack. Figure 20 shows the carbon losses as percent of total carbon input versus the percent volatile matter in the fuel, ranging from the low volatile coal and coke combination to the coals with volatilities close to $40 \%$. The volatility of the coal will also affect the volume and fuel value of the offgas from the shaft furnace and the amount of recirculation and offgas cooling that may be required in the process flowsheet.

\section{Production Rate and Production Intensity}

The successful development and subsequent implementation of a special pipe sampling device, which enabled sampling the slag during blowing in conjunction with copper tracer experiments, led to an estimate of the quantity of metal droplets in the slag originating from the metal bath. These estimates indicate that the quantity of metal droplets suspended in the slag phase during the blow represents 0.6 and 1.2 percent of the weight of the metal bath contained in the converter under so-called "soft" and "hard" blowing conditions, respectively. This is much less than the fraction of the metal bath weight ( 4 percent) suspended as metal droplets in the slag phase as observed by the Japanese in their experiments. The difference can possibly be explained by the relatively low stirring energy ( $1 \mathrm{~kW} /$ tonne) from the bottom gas stirring employed in the AISI converter as opposed to the Japanese practice in which bottom stirring energies up to about $5 \mathrm{~kW} /$ tonne were employed.

Following the analysis of Ibaraki et al published in the Proceedings of the 1990 Ironmaking Conference, the overall apparent rate constant for reduction $\left(\mathrm{kmol} / \mathrm{m}^{2} \mathrm{~min}(\xi \mathrm{Fe})_{\mathrm{T}}\right)$ is shown as a function of the specific slag weight $\left(\mathrm{kg} / \mathrm{m}^{2}\right.$ of vessel cross- 


\section{Pilot Plant Fuel Rates}

\section{$\square$ Raw Data $\square$ Net}

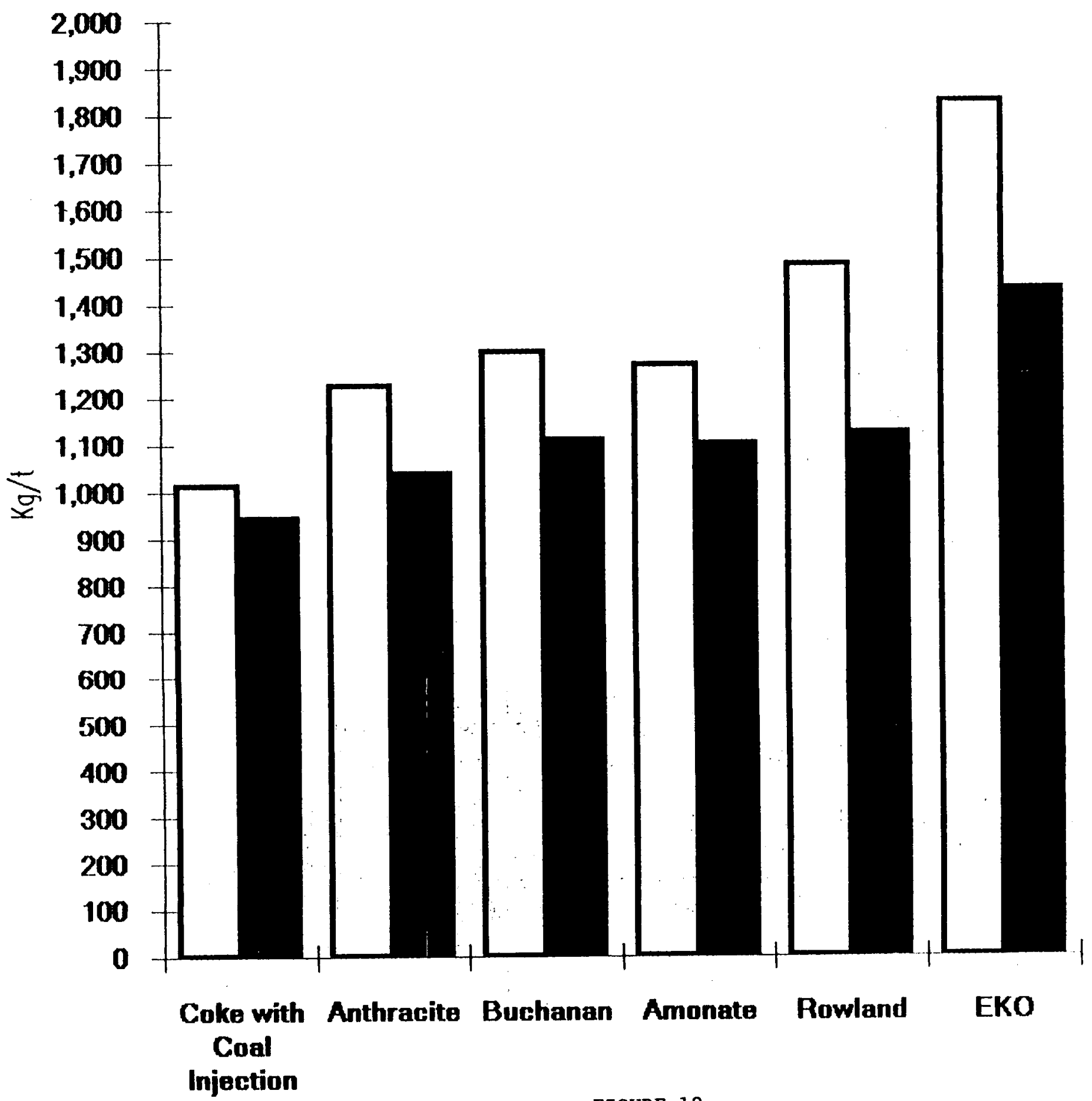

FIGURE 19 


\section{Carbon Losses vs. Volatile Matter}

(Trial Averages)

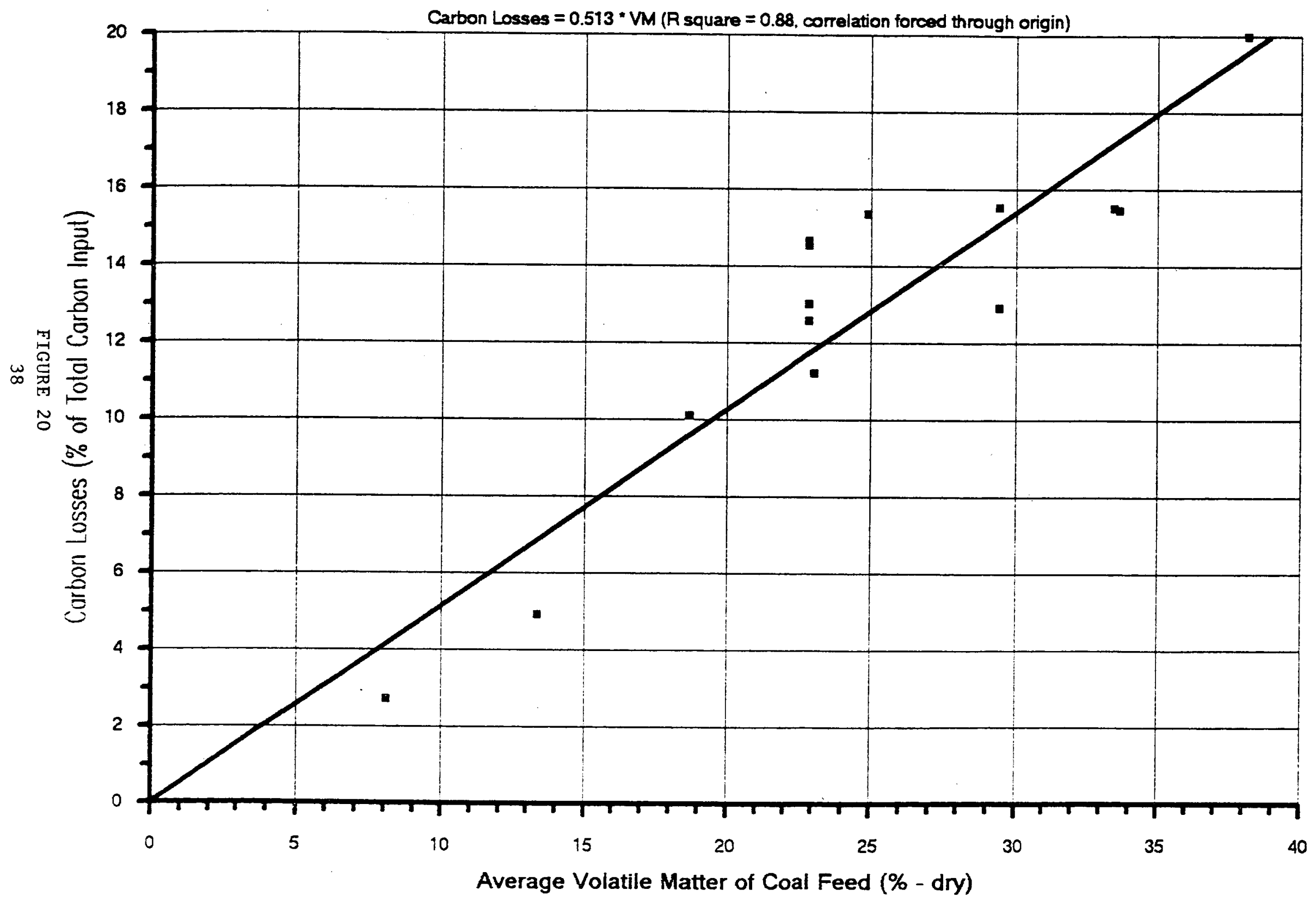


sectional area) in Figure 21. The data derived from the AISI trials are indicated by the various symbols and compared with the data obtained by Ibaraki et al represented by the lower straight line. It is seen that the apparent rate constant for the AISI data is not significantly affected by the type of pellet feed used (Feo or $\mathrm{Fe}_{2} \mathrm{O}_{3}$ ) nor by the blowing conditions ("soft" versus "hard"). Furthermore, it is seen from Figure 21 that the apparent rate constant for reduction observed in the AISI trials is about 50 percent higher than that obtained from the Japanese trials. The reason for this difference is not clear.

Fruehan has converted these production rates to production intensities at operating pressures of one and three atmospheres and obtained intensities of 9.6 and 15 tonnes per cubic meter per day, respectively (see Figure 13, page 12).

\section{Refractory Wear}

The original refractories in the AISI smelter were selected based on expected conditions and oxygen converter experience. During the four lining campaigns, changes were made to the lining based on observed wear behavior, post-mortem analysis, simulated laboratory tests, and thermal and finite element analysis. Table 2 summarizes the evaluation of the lining during the four 1 ining campaigns, and Figure 14, presented earlier, shows a generic view of the lining construction. Briefly, the lining changes made can be summarized as follows:

1. Magnesia-graphite-type brick have replaced the original burned-impregnated magnesia brick in the working lining to improve overall wear resistance.

2. To increase vessel volume, the safety lining thickness was reduced and high-alumina brick replaced the original burned-impregnated magnesia brick to provide equivalent shell temperatures. 


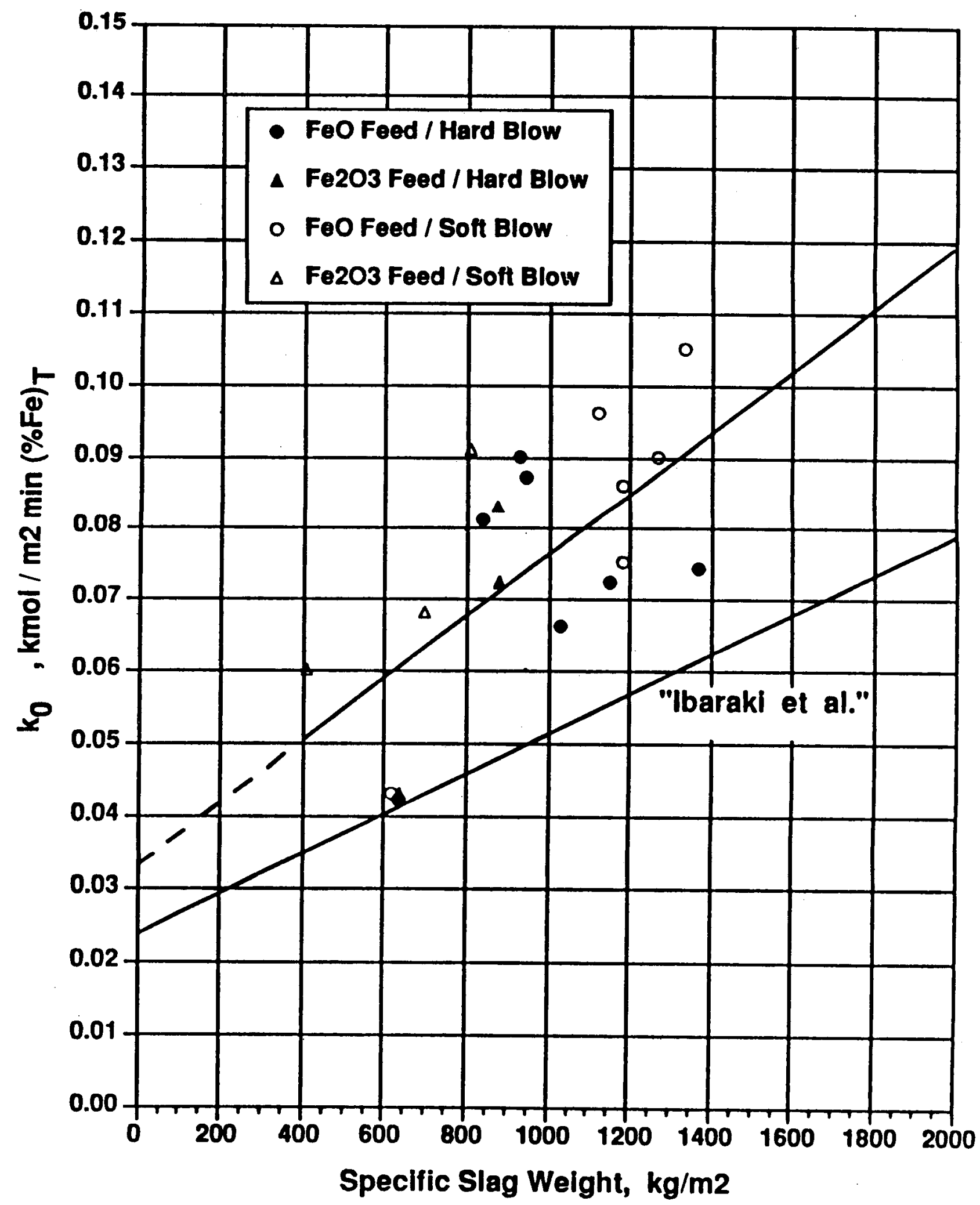

FIGURE 21 
TABLE 2

General Lining Construction in AISI Smelter

AREA *

Safety Lining

Working Lining

Stadium

Barrel

Cone
E

E

D
LINING NUMBER

$1 \quad 2 \quad 3 \quad 4$

A

A

B

C

- $\mathrm{A}=$ burned-periclase brick

$B=70 \%$ alumina brick

$\mathrm{C}=$ special $60 \%$ alumina brick

D = magnesia-graphite brick with fused grain

$E$ = burned-impregnated magnesia brick

$\mathbf{F}=$ magnesia-graphite brick

$\mathbf{G}=$ magnesia-graphite brick premium grade 
3. Details of construction were changed to provide a more stable lining structure. For example, increased vertical expansion allowance was used to avoid damage to bolts connecting the barrel and cone.

The mode of smelter operation involved a series of runs of typical 18 hour preheats and 12 hour operating periods. The wear experience was undoubtably influenced by this periodic operation and the variety of operating conditions investigated. Figure 22 shows the results of wear measured following each run during the fourth lining campaign. Note that the most serious wear is in the transition zone between the barrel and cone. The area corresponds to the postcombustion zone above the foamy slag layer. Post-mortem specimen examination indicates that the wear occurs primarily because of the high temperatures in this zone.

The wear in the most severe zone of the smelter (postcombustion zone) is about $1 \mathrm{~mm}$ per hour, and alternate methods of construction for this zone are under study, including the use of water-cooled panels with or without hot face refractories. Wear in the balance of the smelter is believed to be acceptable with the refractories used in the third and fourth linings.

\section{Phosphorus and sulfur control}

Important considerations in the development of bath smelting processes are the differences (opportunities) these offer in contrast to the classic blast furnace. There are several critical chemistry issues that benefit the smelter technology.

\section{Phosphorus}

The AISI bath smelting process is dependent on the use of a relatively high degree of postcombustion (PCD 40\%) which leads to a slag with an Feo content of 2 to $4 \%$. This results in phosphorus retention capability in contrast to nil for the blast furnace. 


\section{AISI SMELTER REFRACTORY WEAR}

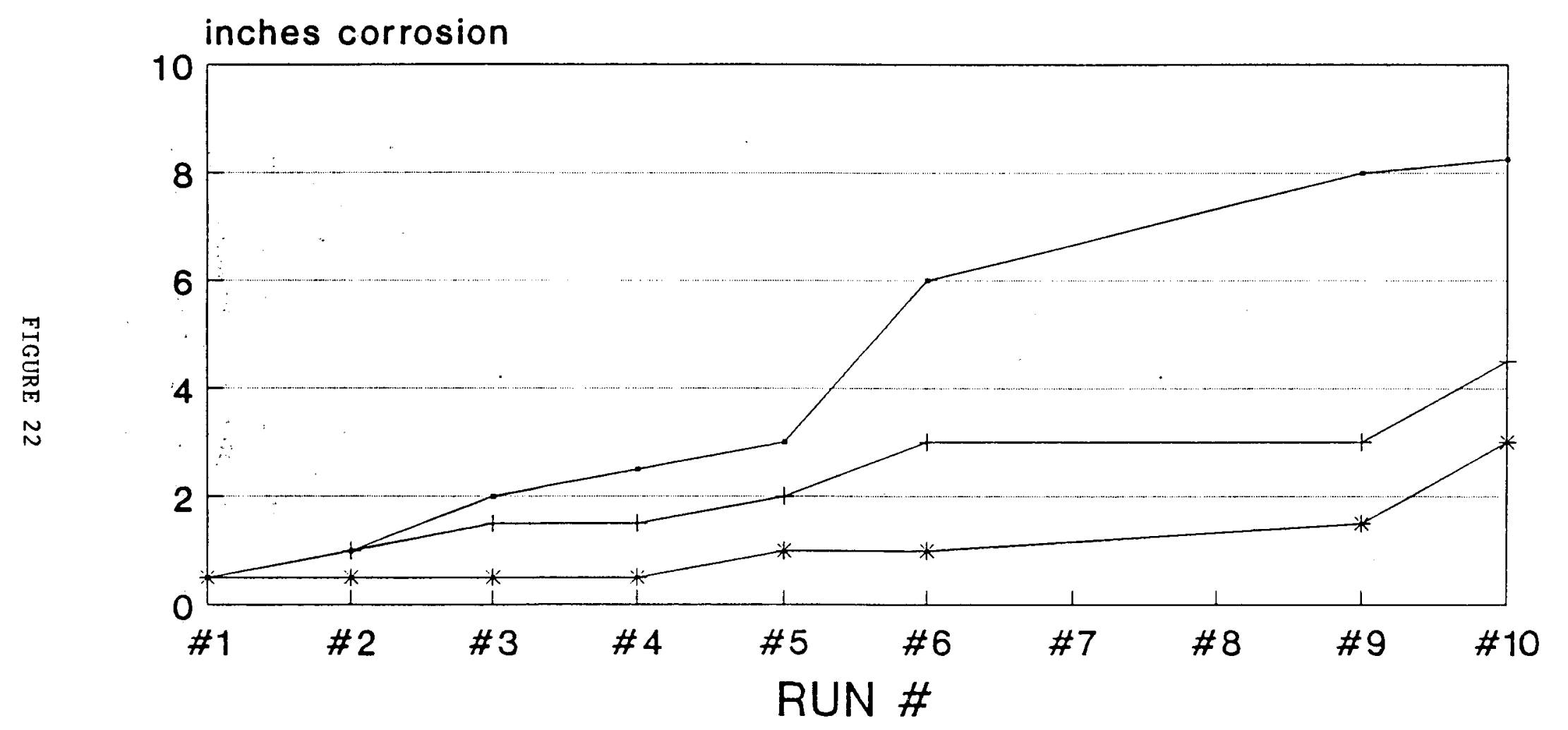

- CONE — BARREL * STADIUM 
Pilot plant data show $\mathrm{P}_{2} \mathrm{O}_{5} / \mathrm{P}-2-20$, and for the typical U.S. pellet, a smelter metal phosphorus content between 0.02 and $0.048 \mathrm{P}$.

Table 3 provides a comparison of phosphorus content between typical U.S. blast furnace practice and the AISI smelter hot metal.

TABLE 3

PHOSPHORUS CONTROL

Bath smelting

\section{P Content}

* Pilot plant performance

- Pellet (Empire)

-- Hot metal (Carbon saturated)

$0.015 / 0.030$

-- Range $\left(\mathrm{P}_{2} \mathrm{O}_{5}\right) / \mathrm{P}$ from 2 to 10

$0.02 / 0.03$

* U. S. blast furnace production

-- Pellet burden, no BOF slag

-- Pellet-sinter burden

Hot metal $0.04 / 0.05$

Hot metal $0.09 / 0.12$

* BOF turndown $\mathrm{P}$ range

steel $0.005 / 0.009$

\section{sulfur}

The blast furnace, because it operates with slags having very low Feo content, e.g. $<1 \%$, is able to hold nearly all the sulfur in the condensed phases, that is, slag and metal. Vapor phase removal is a minor component.

For bath smelting, in both the AISI and the Japanese processes, the situation is much different because the low base/acid ratio and higher Feo content of the slag ( 3 to 5\%) reduces sulfide capacity (and slag/metal partition ratios) so that vapor phase removal of sulfur from the condensed phases becomes an important mechanism. AISI pilot plant data show 80 to $90 \%$ gas phase removal; Japanese range for gas removal is 65 to 75\%. The prevalent species is $\mathrm{H}_{2} \mathrm{~S}$ with a small amount of $\cos$ and with some minor amounts of $s_{2}$ and $\mathrm{SO}_{2}$. The quantity of sulfur to be disposed of from a $1000 \mathrm{NT} /$ day demonstration can range between 1500 and $2000 \mathrm{NT} / \mathrm{Yr}$. 
AISI pilot plant data show that between 85 and 908 of the sulfur introduced by the coal leaves the smelter reaction zone(s) in the gas phase. The extent of interaction between the hot smelter gas and dust is difficult to ascertain; the slag $\left(\mathrm{CaO} / \mathrm{SiO}_{2} \sim 1.5\right.$, Feo - 2 to 4\%) sulfide capacity is very low, and the oxygen potential is set by the postcombustion level of $40 \%$ and the $\mathrm{H}_{2} / \mathrm{CO}$ created by the coal. In addition, about half the sulfur in the coal is organic, so it enters the gas phase at the time the other volatiles leave the coal.

Thermodynamic arguments point to the probability that the prevalent sulfur containing gaseous species within the smelter is $\mathrm{H}_{2} \mathrm{~S}$, with small amounts of $\mathrm{COS}, \mathrm{SO}_{2}$, and $\mathrm{S}_{2}$. As the gas cools from $1600^{\circ} \mathrm{C}$ and approaches $900^{\circ} \mathrm{C}$, the sulfur form is $\mathrm{H}_{2} \mathrm{~S}$ and $\cos (9 / 1$ ratio) with reaction of sulfur with the Feo portion of the smelter dust occurring if the gas reaches below $900^{\circ} \mathrm{C}$.

AISI pilot plant sludge samples taken after the scrubber show significant $S$ content (20 to $40 \%$ of charge sulfur). These figures are indications of part of the sulfur path, Figure 23, but a far more rigorous investigation of the matter is necessary to define the most effective manner to dispose of the sulfur load.

There are several options for sulfur management:

* Operate with a hot cyclone at $\geq 950^{\circ} \mathrm{C}$ to prevent conversion of Feo in the dust to Fes (and without free lime/dust cas formation). This results in lowest $s$ metal as recycle is preventable. However, to make this work, all the sulfur in the gas stream must be captured in a lime/dolomite shaft ahead of the prereducer for removal of Cas and Mgs. This is not a desirable solution as these products are not disposed of readily.

* Allow for formation of Cas and Fes in the hot cyclone by operation at $\leq 950^{\circ} \mathrm{C}$ and promote capture of sulfur in the prereducer, thus removing nearly all sulfur from the tail 
Smelter Flowsheet - Possible Sulfur Balance With Flux To Shaft \& A High Sulfur Recirculation Rate




gas. This is practical only if the sulfur returned to the smelter as Cas is actually held by the slag (vs. immediate release to the gas phase). Tests are planned at Universal.

* Operate as above, but without capture of sulfur in the prereducer. This would result in a tail gas from the prereducer containing up to $0.245 \% \mathrm{H}_{2} \mathrm{~S}$, or $0.125 \% \mathrm{SO}_{2}$ after combustion in a waste heat boiler. Technology and costs for this alternative are known.

These options continue to be assessed, and the environmental consequences are being taken into account.

\section{TASR 4 - MATHEMATICAL AND PHYSICAL MODELING}

\subsection{1 - McMaster/MCGill}

\section{Postcombustion and Heat Transfer Modeling (McMaster)}

To support the postcombustion experiments in Dofasco's KOBM for the AISI Direct steelmaking Program, a mathematical model has been developed at McMaster to describe fluid flow, combustion reactions, and heat transfer (including radiation) in a two-dimensional, turbulent system. The model has been used to simulate flow patterns, combustion reactions, heat transfer, and the thermal state of Dofasco's KOBM under normal operating conditions. This work was concluded in early 1991. Figure 24 shows a comparison of the heat transfer rate in the vessel between Dofasco's in-plant measurements and model predictions. General agreement between the heat transfer flux calculations based on the model and those measured industrially confirmed the validity of the model for combustion and heat transfer calculation in the "freeboard" of the converter-type furnaces. Through this modeling work, the main conclusions are: 


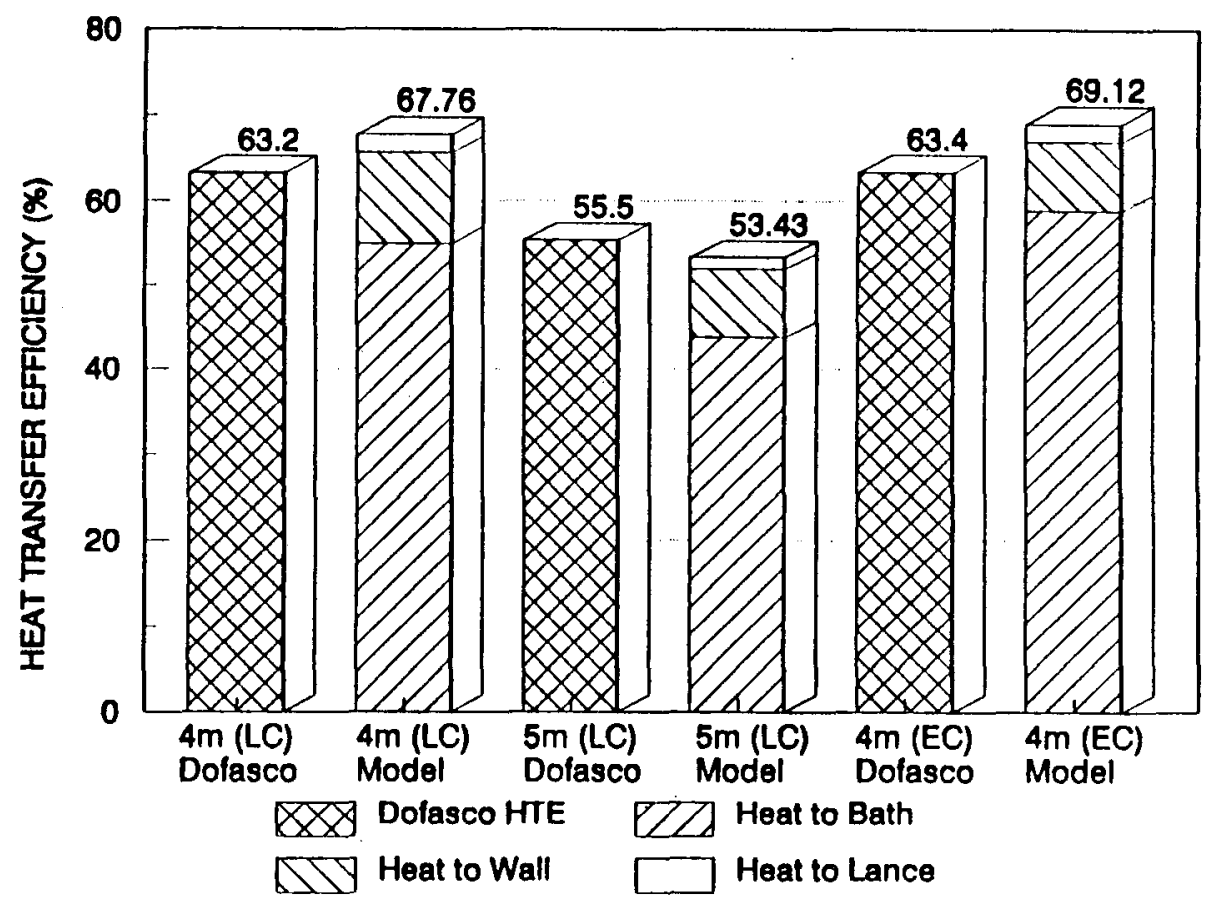

Comparison of heat transfer efficiency (HTE) between Dofasco's measured values and mathematical modelling results. $4 \mathrm{~m}(\mathrm{EC}): 4 \mathrm{~m}$ lance height early in campaign; $4 \mathrm{~m}(\mathrm{LC}): 4 \mathrm{~m}$ lance height late in campaign where the vessel is large due to refractory erosion; $5 \mathrm{~m}(\mathrm{LC}): 5 \mathrm{~m}$ lance height late in campaign.

FIGURE 24 
* the postcombustion ratio is determined from the rates of oxygen supply, oxygen used for decarburization, and the remainder available for postcombustion,

* the conventional defined heat transfer efficiency overestimates the heat recovered by the bath by about $20 \%$ due to loss to the surroundings,

* radiation plays an important role in heat transfer from the high temperature flame to the liquid bath, and

* the location of the combustion zone can be controlled, to a certain extent, by adjusting the lance practice.

Postcombustion Degree (PCD) Calculation (MCMaster)

Through analysis of the operational data from Dofasco trials, it has been found that postcombustion degree (PCD) is deducible from a simple mass balance calculation without the data from offgas composition analysis. Based on iron, coal, and oxygen input rates, a model and the corresponding computer code for mass balance and PCD calculation in smelting processes has been established.

starting in 1991, this method was used to calculate PCD in the AISI pilot plant vertical smelter trials. This model has proven to be simple and effective. Moreover, it will be more useful in a largescale furnace where steady-state operation becomes more soundly guaranteed. This program can be installed in the plant on-line computer system for process operation control.

\section{Foaming Slaq Modeling (McMaster)}

Based on multi-phase fluid dynamic fundamentals, a mathematical model has been developed to describe two-phase flow characteristics in a foaming slag in smelting reduction processes. Gas and liquid volumetric fractions, apparent slag density, and, most importantly, foaming slag level can be determined from this model. 
From AISI pilot plant trial meaburements on foaming slag level and operational parameters, the key parameter, $C_{D} / d_{b}$, the ratio of $d r a g$ force coefficient to gas bubble diameter, required in the model has been extracted. General agreements on $c_{D} / d_{b}$ values among experimental data from the Nippon steel pilot smelter, the Linde water model, and the AISI pilot plant vertical smelter strongly support the validity of this model.

Application of this model to calculate the dynamic foaming slag level in the AISI pilot plant has shown very good agreement between plant-measured data and model predictions. Figure 25 is an example of the calculated foaming slag levels compared to the measured ones in one of the AISI pilot plant trials.

This model can also be applied to the horizontal smelter and largescale smelting furnace for effective control of slag foaming. The model for mass balance and PCD calculation discussed in the previous section and the model for foaming slag can be combined to form an integrated model to be used in process control.

\section{Coal Injection (McMaster)}

A few trials with coal/nitrogen injection were conducted in the AISI pilot plant vertical smelter. The results were analyzed and interpreted by McMaster personnel. From this limited information, it is found that volatile matter recovery improved while postcombustion degree decreased with the injection of $10-20 \%$ of the coal under the slag layer. From a thermal energy point of view, coal consumption could be significantly reduced through efficient recovery of volatile matter by coal injection.

A mathematical model is being developed to describe the coal/nitrogen jet trajectories in liquid slag and/or metal and to study the potential of the coal injection. The jet velocity, expansion, incline angle, and composition changes can be determined by using this model. Figure 26 shows the trajectory of a coal/nitrogen jet injected in the slag layer from model 


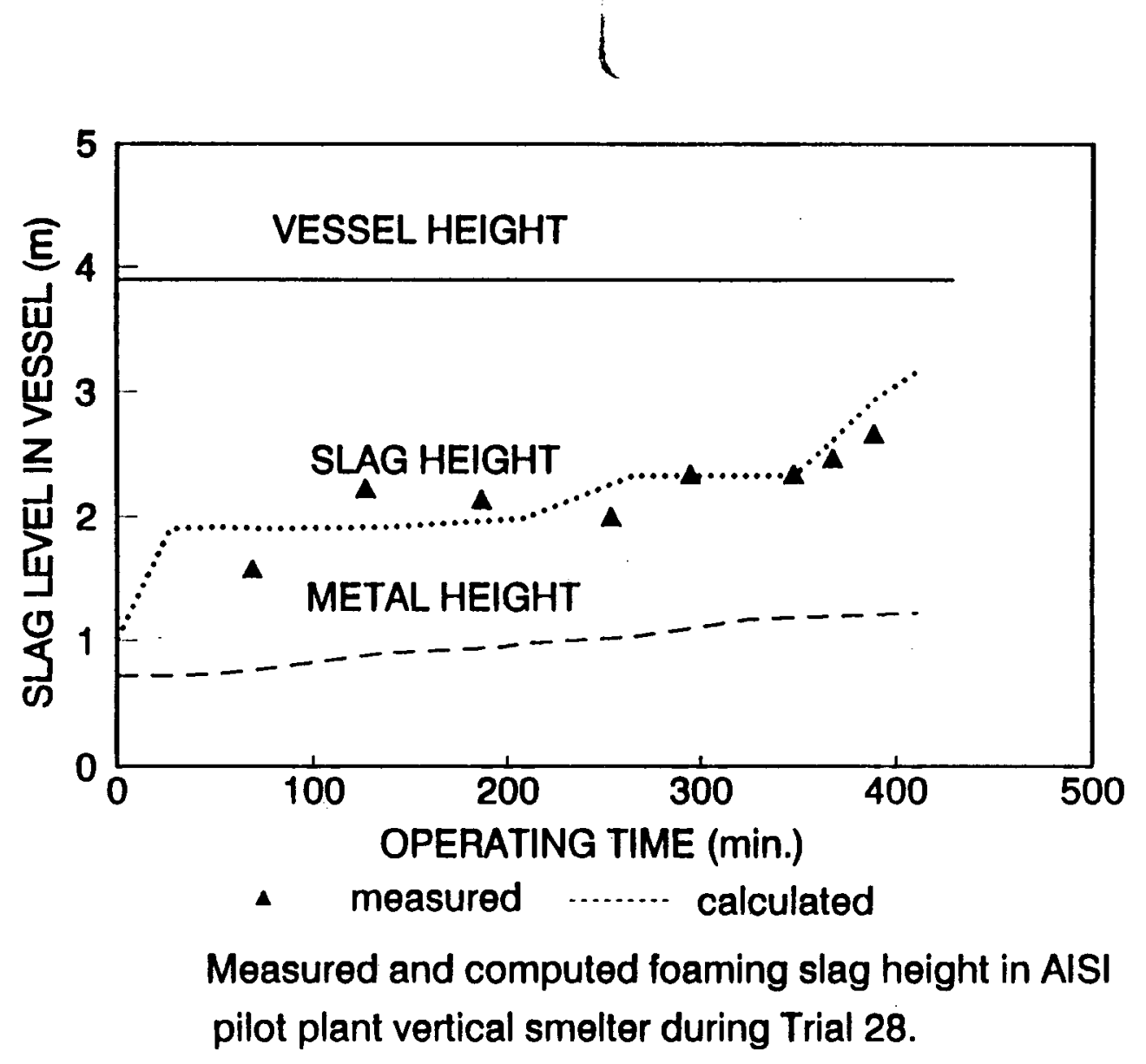

FIGURE 25 


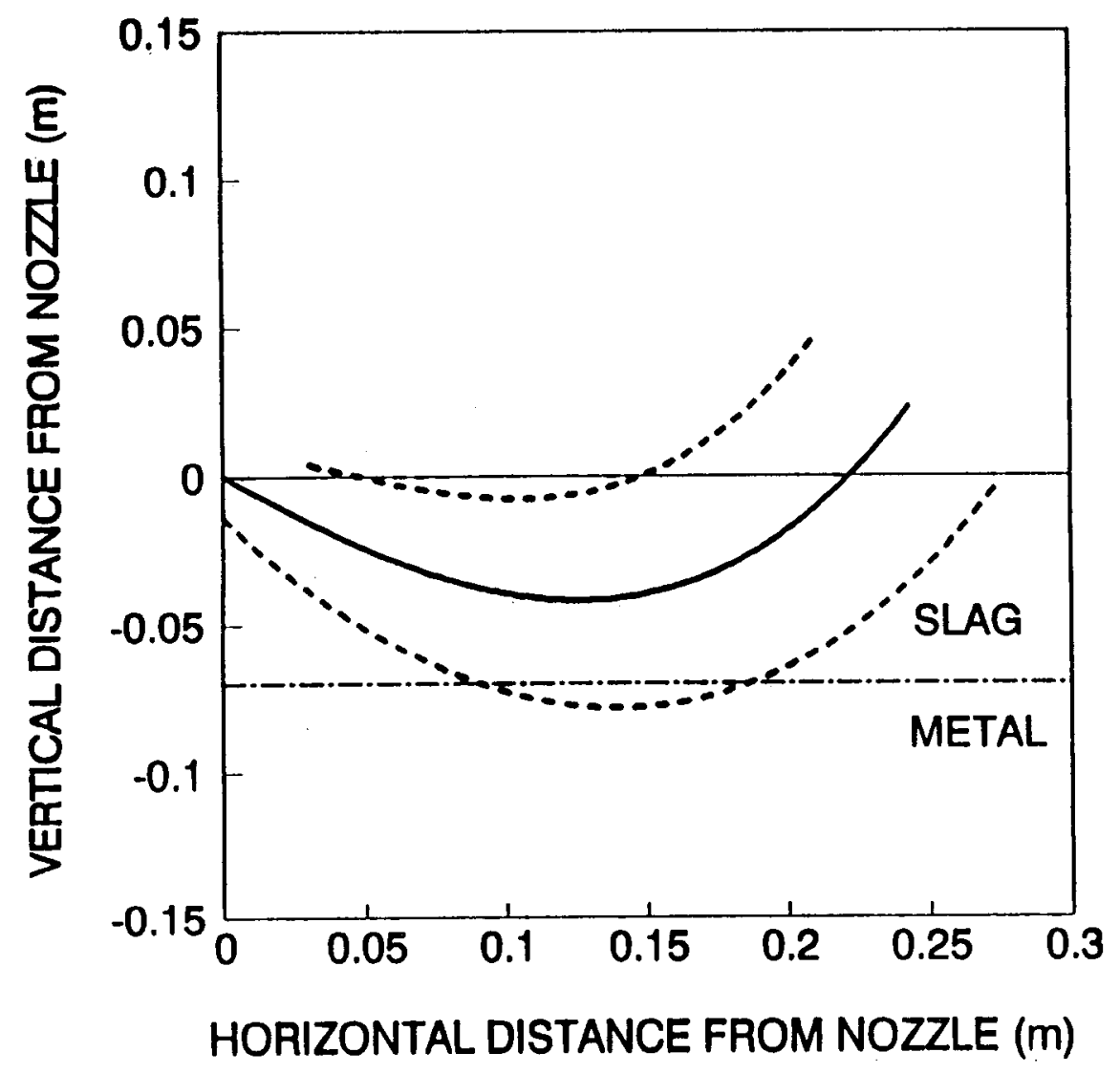

Computed coal/nitrogen jet trajectory injected in slag layer. Coal $/ \mathrm{N}_{2}=12 \mathrm{~kg} / \mathrm{Nm}^{3}$, jet angle $=27.5^{\circ}$, nozzle diameter $=0.0183 \mathrm{~m}$.

FIGURE 26 
computation. The model will be used to assist the engineering design and plant operation of coal injection into the horizontal smelter.

\section{oxygen Jet Modeling (McMaster)}

To assist the oxygen lance design and operation of the horizontal smelter, a mathematical model is being developed to describe oxygen jet behavior in the smelter. The oxygen jet trajectories and their interactions with the surrounding atmosphere and liquid slag as well as the oxygen concentration distribution in the vessel can be calculated with this model. Parameters such as lance position, jet angle, and initial velocity and their influences on jet behavior can be investigated by this model. Some preliminary modeling results show that this model is a useful tool in both oxygen lance engineering design and oxygen jet mechanism study.

\section{Physical Modeling of the Vessel (McGill)}

A one-half scale "thin slice" model of the AISI vertical vessel was constructed at MCGill University to simulate the fluid flow patterns generated through the introduction of nitrogen stirring gas and from the gas generated from the smelting reactions in the slag. A porous plate adjacent to the slag-simulating phase (silicone oil) enabled high gas flow rates to originate from this phase. The results indicated that the top oxygen jet penetration into a foamy slag was equivalent to that in an unfoamed slag, presumably because the upward flow of gas compensated for the low density of the foamed slag. Droplet generation of the metalsimulating phase (an aqueous zinc chloride solution) was uniform across the diameter of the vessel. The gradient in the vertical direction was very large; for example, under conditions chosen to simulate the AISI vertical vessel (gas fraction 0.3 ), at $20 \%$ of the silicone height, there was 25 volf fraction of $z$ inc chloride suspended in the silicone. This value dropped to 15 volz at $40 \%$ of the silicone height. 


\section{Future Work (McMaster)}

The following work will be carried out at McMaster in the upcoming year:

* Close cooperation between the AISI pilot plant and McMaster will continue to assist the plant design and data interpretation,

* The coal/nitrogen jet model will be modified to accommodate the heat transfer and chemical reactions, especially the devolatilization of the coal, within the jet,

* The oxygen jet model will be modified to accommodate the heat transfer between the jet and surrounding gas and combustion reactions with the jet, and

* study of the interaction between oxygen jet stream, coal/nitrogen jet stream, and iron ore charging stream will be undertaken.

TASK 4 - PHYSICAL MODELS, HEAT TRANSFER,

\section{PARAMETRIC MODELS}

Task 4.3.2 - Union Carbide Industrial Gases

\section{Parametric Model}

A basic parametric model had been developed in 1990. Model enhancement and application to AISI pilot plant smelter trials have been accomplished during this reporting period. The major model enhancements included (a) calculating sulfur balance in the smelter and (b) calculating the flux feed rate based on the aim slag basicity. The model application included (a) redefining each zone to accommodate the AISI vertical smelter system and (b) comparing 
the model calculations against the smelter test result. Table 4 shows an example of such a comparison. It can be seen from the table that the model calculation is in good agreement with the experimental data. The $\mathrm{H}_{2} / \mathrm{C}$ ratio may provide the best check between the measured values and the model values because this ratio is independent of any air infiltration.

The parametric model was coded in a QuattroPro spreadsheet form to facilitate its usage. The input and output layout is presented in Table 5. As shown, the model is able to handle a wide range of smelting conditions. These are:

1. Different ore composition (from hematite to wustite) and ore preheating temperature.

2. Different coal type.

3. Different dust loss, dust composition, and percentage of dust recycle.

4. Different postcombustion degree.

5. Different heat loss through the smelter.

6. Different levels of $\mathrm{Fe}, \mathrm{FeO}$, and char loss through slag tapping.

once the inputs are given, the model calculates the following outputs based on mass and energy balances:

1. Coal, ore, flux, and $\mathrm{O}_{2}$ feed rates.

2. Slag formation rate.

3. Slag composition.

4. Smelter offgas volume and composition.

5. Ratio of $\mathrm{O}_{2}$ gas reacted with smelter gas to that with solid carbon, an equivalent parameter to "J value" defined by the Japanese.

In addition to the development of the parametric model, a heat transfer study in the head space of the AISI horizontal vessel has been conducted under this task. The study primarily aimed at estimating the total heat loss through a water-cooled roof. It was 
TABLE 4

MODEL VALIDATION

Model inputs (from the analytical model): $24 \%$ PCD
$40 \%$ VM Bypass

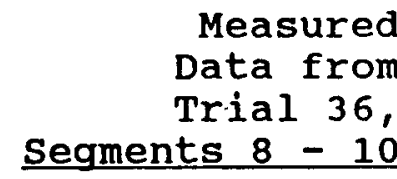

Data from

Trial 36,

Segments $8-10$

$\operatorname{Coal}(\mathrm{kg} / \mathrm{t})$

Coal $(\mathrm{kg} / \mathrm{h})$

Ore $(\mathrm{kg} / \mathrm{h})$

oxygen $\left(\mathrm{NM}^{3} / \mathrm{h}\right)$

\section{Smelter offgas}

\& $\left(\mathrm{CO}+\mathrm{CO}_{2}\right)$

$\left(\mathrm{H}_{2}+\mathrm{H}_{2} \mathrm{O}\right)$

\& $\mathrm{N}_{2}$

$\& \mathrm{Ar}$

$\mathrm{H}_{2} / \mathrm{C}$

PCD (\%)

73.60

22.67

1.20

2.64

0.31

21.70

Duct gas

$$
\begin{aligned}
& \text { \& }\left(\mathrm{CO}+\mathrm{CO}_{2}\right) \\
& \&\left(\mathrm{H}_{2}+\mathrm{H}_{2} \mathrm{O}\right) \\
& \text { \& } \mathrm{N}_{2} \\
& \text { \& } \mathrm{Ar} \\
& \mathrm{H}_{2} / \mathrm{C}
\end{aligned}
$$

37.23

17.46

42.20

1.74

0.47
Parametric

Model

1411

4593

5088

2331

72.39

22.10

2.76

2.74

0.31

24.10

38.51

18.28

42.20

1.74

0.47
Difference

(各)

$$
\begin{gathered}
1.2 \\
0 \\
-18
\end{gathered}
$$

$$
\begin{gathered}
-1.6 \\
-2.5 \\
130 \\
3.8 \\
0 \\
11.1
\end{gathered}
$$




\begin{tabular}{|c|c|c|c|}
\hline 4 & Ore Information & & \\
\hline 5 & Fe 203 content (wt\%) & $9.49 \%$ & $9.49 \%$ \\
\hline 6 & Fe 304 content $(w t \%)$ & $0.00 \%$ & $0.00 \%$ \\
\hline 7 & Feo content $(w t \%)$ & $74.71 \%$ & $74.71 \%$ \\
\hline 8 & SiO2 content (wt\%) & $5.22 \%$ & $5.22 \%$ \\
\hline 9 & $\mathrm{CaO}$ content (wt\%) & $6.40 \%$ & $40 \%$ \\
\hline 10 & MgO content (wt\%) & $5 \%$ & $95 \%$ \\
\hline 1 & Ore input temperature $(K)$ & 300 & 300 \\
\hline 13 & Coal Information & & \\
\hline 14 & Moisture content & $3.7 \%$ & $2.6 \%$ \\
\hline 5 & Ash content (dry) & $6.5 \%$ & $8.5 \%$ \\
\hline 6 & wt\% of SiO2 in coal ash & $59.3 \%$ & $37.7 \%$ \\
\hline 7 & w.t $\%$ of Al203 in coal ash & 28 & $.9 \%$ \\
\hline 8 & Volatile matter (dry) & & $.8 \%$ \\
\hline 9 & C content (dry) & 82. & $82.5 \%$ \\
\hline 0 & H content (dry) & $4.8 \%$ & $4.3 \%$ \\
\hline 1 & O content (dry) & 4 . & $2.9 \%$ \\
\hline 2 & $N$ content (dry) & $1.5 \%$ & $1.2 \%$ \\
\hline 3 & S content (dry) & $0.7 \%$ & $0.7 \%$ \\
\hline 24 & $\%$ of $S$ released during pyrolysis & $50.0 \%$ & $50.0 \%$ \\
\hline 25 & $\%$ of moisture evolved in off-gas & $0 \%$ & $.0 \%$ \\
\hline 26 & $\%$ of VM evolved in off-gas & $10.0 \%$ & $.0 \%$ \\
\hline 27 & Coeff. rel. to heating coal in $O G$ & 0 & 0 \\
\hline 28 & Coal heating value (kcal/kg dry) (net) & 7710 & 7710 \\
\hline 9 & & & \\
\hline 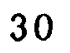 & Dust Information & & \\
\hline 1 & Total dust weight $(\mathrm{kg} / \mathrm{hr})$ & 1000 & 0 \\
\hline 2 & Char content in dust (wt\%) & $50.0 \%$ & $50.0 \%$ \\
\hline 33 & Fe content in dust $(w t \%)$ & $5.0 \%$ & $5.0 \%$ \\
\hline 34 & FeO content in dust (wt\%) & $25.0 \%$ & $25.0 \%$ \\
\hline 35 & $\%$ of dust Char generated in OG zone & $0.0 \%$ & $0.0 \%$ \\
\hline 36 & $\%$ of dust recycled & $0.0 \%$ & $0.0 \%$ \\
\hline $\begin{array}{l}37 \\
38\end{array}$ & Temp. of the recycled dust $(K)$ & 300 & 300 \\
\hline 39 & Production Rate (ton/hr) & 3 & 3 \\
\hline 40 & Wt. $\%$ of $\mathrm{C}$ in hot metal & $5.0 \%$ & $5.0 \%$ \\
\hline 41 & PCR in the smelting zone & $25.0 \%$ & $25.0 \%$ \\
\hline 42 & Bottom $N 2\left(\mathrm{Nm}^{\wedge} 3 / \mathrm{hr}\right)$ & 160 & 160 \\
\hline 43 & Bottom $02\left(\mathrm{Nm}^{\wedge} 3 / \mathrm{hr}\right)$ & 0 & 0 \\
\hline $\begin{array}{l}44 \\
45\end{array}$ & Heat loss (kcal/hr) & $4.50 \mathrm{E}+05$ & $4.50 E+05$ \\
\hline 46 & Slag basicity (B/A) & 1.7 & 1. \\
\hline 47 & Wt\% of CaO in the flux & $75.0 \%$ & $75.0 \%$ \\
\hline 48 & wt\% of FeO in the slag & $3.00 \%$ & $3.00 \%$ \\
\hline 49 & $\mathrm{~kg} \mathrm{Fe}$ in one $\mathrm{kg}$ slag & 0.000 & 0.000 \\
\hline 50 & kg char in one $\mathrm{kg}$ slag & 0.000 & 0.000 \\
\hline 51 & $S$ partition ratio ( $\% S$ in slag/\%S in $H M)$ & 8.00 & 8.00 \\
\hline $\begin{array}{l}52 \\
53\end{array}$ & $\%$ of offgas $s$ re-adsorbed by ore & $0.0 \%$ & $0.0 \%$ \\
\hline 54 & Temperature in the FR zone $(\mathrm{K})$ & & \\
\hline 55 & Temperature in the TR zone (k) & & \\
\hline 56 & Temperature in the PC zone $(\mathrm{K})$ & 1873 & 1873 \\
\hline
\end{tabular}


TABLE 5 (cont.)

GENERAL OUTPUT

Case \# (see Description \& Comment)

1

$\begin{array}{cc}+814.2 & 4813.7 \\ 2444.8 & 2233.9 \\ 1.098 & 0.927 \\ 4053.5 & 3722.2 \\ 336.4 & 277.4 \\ 23.3 \% & 23.4 \% \\ 1234.3 & 1220.4 \\ 0.0 & 0.0 \\ 0.0 & 0.0\end{array}$

$\begin{array}{rr}3.00 \% & 3.00 \% \\ 30.34 \% & 28.42 \% \\ 4.86 \% & 1.33 \% \\ 45.41 \% & 42.29 \% \\ 14.42 \% & 13.37 \% \\ 0.72 \% & 0.61 \% \\ 1.26 \% & 7.97 \%\end{array}$

$96.44 \%$

6912.7

$96.65 \%$

6195.5

$\begin{array}{rr}2.92 \% & 3.08 \% \\ 15.61 \% & 14.07 \% \\ 12.91 \% & 12.11 \% \\ 57.20 \% & 58.63 \% \\ 11.36 \% & 12.12 \% \\ 0.416 & 0.370\end{array}$

$1604.7 \quad 1604.6$

$814.9 \quad 744.6$

1351.2

112.1

411.4

2304.2

2450.1

0. $090 \%$

1240.7

92.5

406.8

2065.2

2175.3

$0.077 \%$

1762.1

7350.4

1783.5

97 Of $\mathrm{f}$-gas temperature 2 (K)

98 H.T. efficiency 2

99 off-gas volume $2\left(\mathrm{Nm}^{\wedge} 3 / \mathrm{hr}\right)$

100 Off-gas composition 2 (Vol.\%)

$101 \quad$ N2

$102 \quad H 2$

$103 \quad \mathrm{H} 2 \mathrm{O}$

$104 \quad \mathrm{CO}$

$105 \quad \mathrm{CO} 2$

$106 \mathrm{H} 2 / \mathrm{C}$ ratio in off-gas 2

107

108 Freq. of mass Cir. (FR \& TR) (cyc/min)

109 Freq. of mass Cir. (PC \& FR) (cyc/min)
$100.4 \%$
$2.81 \%$

$18.44 \%$

$12.48 \%$

$56.14 \%$

$10.13 \%$

0.467
$99.6 \%$

6526.0

$2.97 \%$

$16.54 \%$

$11.89 \%$

$57.76 \%$

$10.83 \%$

0.414

$8.64 \quad 9.94$

$13.29 \quad 15.28$

110

111 DESCRIPTION \& COMMENT: (Case descriptions \& conmments nay

112 * Comparison of Med-Vol \& Hi/Med-Vol coals.

113 * Wustite feeding, top charge.

114 
found from the study that radiation is the dominant heat transfer mechanism and that the total heat loss through the roof ranges from 2 to $3 \mathrm{milli}$ in $\mathrm{kcal} / \mathrm{hr}$ under typical AISI smelting conditions. The effect of roof wall temperature on heat loss was also studied.

\section{oxygen Jet}

oxygen jet flame characterization has continued this year. Two types of oxygen jet experiments have been conducted. They are (a) non-reacting jet test and (b) reacting jet test. The jet tests were performed in a high temperature furnace with non-reacting and reacting atmospheres to simulate the oxygen jets in a smelter. Jet velocities of $262 \mathrm{ft} / \mathrm{s}$ to $1123 \mathrm{ft} / \mathrm{s}$ corresponding to Mach number 0.24 to 1.0 were used in the experiments. The oxygen concentration profiles of the jets were measured within 10 to 120 nozzle diameters from the oxygen lance tip. These profiles were compared to one another and to conventional jet formulas to identify the effects of chemical reaction as well as density of the surrounding gas on the jet behavior.

It was found that the oxygen jet entrainment under the experimental conditions was less than that predicted by the conventional jet formulas. This phenomena, so-called jet coherency, was more pronounced in the high velocity reacting jet test. As a result, the measured jet flame length was much longer than that calculated by the jet formula. Therefore, the conventional jet formulas are not recommended for the smelter oxygen jet design.

\section{AOD Refining}

The flowsheet option of using an AOD vessel to refine the output metal from the horizontal smelter was evaluated. Demonstrated process refining capability indicates that aim carbon and sulfur levels can be readily achieved and that practices could be developed to meet the aim nitrogen levels as well. This combined refining capability would eliminate the need for both a hot metal desulfurization station and vacuum capability at the ladle refining 
station, thereby reducing capital and operating costs. Meeting the cleanliness (oxygen content) requirement would require simple aluminum wire feeding and argon rinsing capability at the ladle station.

The overall conclusion of the effort to evaluate various flowsheet options for refining is that AOD is a low capital option with fewer refining steps and high metal yield. Desired quality levels can be achieved with modest additional ladle refining required for inclusion control. Refractory consumption in the AOD will be higher than the BOF option, but this will be partially compensated by the elimination of hot metal refining and vacuum degassing.

\section{Volatile Matter Bypass}

The parametric model zone definitions were modified to accommodate the volatile matter bypass experienced during the medium to high volatile coal smelter trials. The model. was used to analyze postcombustion performance, interpret oxygen jet behavior, and provide recommendations for optimizing oxygen injection practices for the vertical smelter.

Based on the result from the oxygen jet study, the oxygen jets in a smelter are usually coherent. This jet coherency behavior prevents the jet entrainment from surrounding gas, resulting in

poor gas phase mixing. Therefore, distribution of oxygen through the oxygen jet design is necessary in order to achieve a high postcombustion degree. This aspect of oxygen jet behavior in a hot reacting environment was integrated into recommendations for oxygen lance designs and practices.

The inputs from the parametric model and oxygen jet studies combined to provide an interpretive capability and basic oxygen jet understanding which helped to guide the empirical test program that was conducted to evaluate and optimize vertical smelter performance with medium to high volatility coals. This effort will continue next year in support of the optimization of the horizontal smelter. 


\section{TASK 6 - TECHNOECONOMIC ANALYSIS}

The technoeconomic evaluation of the direct steelmaking process is positive. There are several technically feasible options involving the smelting process under development to process hematite pellets to steel or even to ultra-low-carbon steel. All the research, development, physical and mathematical modeling, and pilot plant operation continue to show promise. No obstacles to success have been discovered. The economic evaluation of several alternative flowsheets by two AISI member companies show promise in that variable operating costs are comparable to those for the blast furnace/BOF process, varying from somewhat higher to significantly lower, depending on coal costs and certain site-specific assumptions. Coal use and overall energy requirements are also lower for the smelter process.

Preheating and prereducing in a shaft furnace have been evaluated by HYLSA. As the result of pilot scale experimentation and production of over 500 tonnes of wustite for use in the pilot smelter, HYLSA concluded that a moving-bed shaft furnace could be coupled to the smelter and provide the preheated wustite and flux to the smelter. They also provided design specifications for a pilot furnace and a commercial furnace and provided materials and energy requirements for a flowsheet leading to the production of one million tons of liquid steel.

Pilot plant data were used as a basis for the material and energy requirements for the single-zone vertical vessel smelter flowsheets, Figure 16, presented earlier.

Refining processes included continuous desulfurization and continuous decarburization, BOF refining, AOD refining, and electric furnace (EAF) refining. Continuous desulfurization has been demonstrated by General Motors in this country, and continuous decarbonization has been demonstrated by IRSID in France. Material and energy requirements were developed in conjunction with personnel from these organizations. BOF and EAF refining are 
practiced widely and material and energy requirements are wellknown. The AOD refining assumed is non-standard and was developed for the $0.5 \mathrm{C}$ hot metal from the two-zone smelter in conjunction with personnel from Union Carbide Industrial Gases, developers of the process.

Flowsheets were developed, Figure 27, for processes leading to the production of one million tons of liquid steel. Except for the EAF. cases, where more scrap is used, all flowsheets used scrap at the rate of about 25\%. Because no more scrap could be added for some of the refining processes for the $0.5 \mathrm{c}$ hot metal from the two-zone smelter, cases were evaluated wherein the required scrap was added to the smelter. Also, because the continuous desulfurization process requires silicon in the hot metal, ferrosilicon was added prior to desulfurization in that flowsheet. The differing volatilities of coal required differing treatments of the smelter offgas to achieve the proper temperature and energy value for transfer to the shaft furnace.

The variable operating costs forecast for the smelter flowsheets are encouraging. Capital costs, that must be estimated before analyses are complete, will likely favor the smelter flowsheets even more. The detailed technoeconomic analysis is the subject of a confidential internal report.

\section{TASR 7 - PATENTS, TALRS, pUBLICATIONS}

\section{Patents}

The Steel Technology Corporation has filed U. S. Patent Application Serial No. 07/736,626 entitled "Two-zone Countercurrent Smelter system." 
FLOH CIIART FOR STEELMAKING FROM CARBON SATURAIED IRON

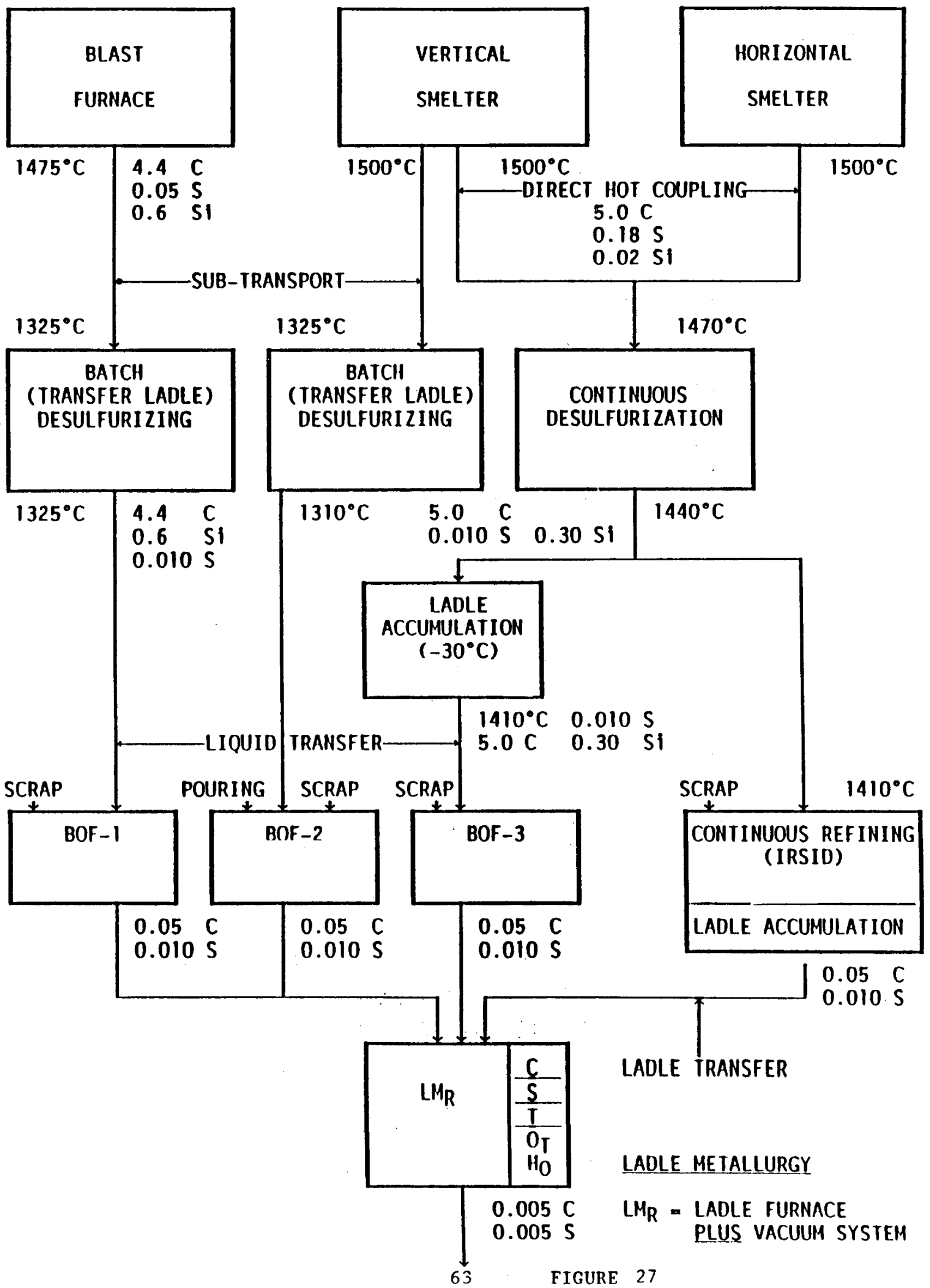


Talks

TMS Annual Meeting, New Orleans, Louisiana, February $16-21,1991$.

"Observations of the Reaction of Oxide Pellets with Liquid Fe-C Melts, $1200-1650^{\circ} \mathrm{C}$," G. G. Krishna Murthy and John F. Elliott.

AISE Iron and steel Exposition, Pittsburgh, Pennsylvania, September $23-26,1991$.

"AISI/DOE Direct Steelmaking Program Update," John M. Farley.

Third U. S. - Japanese Joint Symposium on Bath Smelting and Clean steel, October $7-9,1991$, Myrtle Beach, South Carolina.

"Fundamentals of Bath Smelting," R. J. Fruehan.

"Gas/Metal/Slag Interactions in the AISI/DOE Bath Smelting Process," G. J. W. Kor, M. Schlichting, and

K. B. Downing.

"Sulfur Paths in Bath Smelting," P. J. Koros, A. E. Morris, J. C. Myers, and H. R. Pratt.

\section{Publications}

"Iron Bath Smelting - Current status and Understanding," R. J. Fruehan, Proceedings of the Elliott symposium on Chemical Process Metallurgy, June $10-13,1990$, issued 1991.

"The AISI Direct Steelmaking Program," E. Aukrust and K. B. Downing, 1991 Ironmaking Conference Proceedings, pgs. $659-663$. 
Much of the work conducted by CMU, MIT, McGill, and McMaster has been prepared for publication and is expected to issue in 1992 in professional society publications.

\section{Funding}

The AISI-DOE Direct steelmaking Research Program has been budgeted through Fiscal 1991 for $\$ 33,361,000$, of which $77 \%(\$ 25,661,000)$ has been funded by the federal government.

\section{TASK 8 - PHY8ICAL MODELING OF THE TWO-ZONE SMELTER}

Kinetic models indicate that the rate of reduction in a two-zone countercurrent smelter can be significantly higher than for a single-zone smelter. There is also the potential of producing metal of lower carbon content $(1-2 \%)$. The two-zone smelter concept depends on the ability to maintain the desired concentration gradients in the slag and metal. To test the feasibility and to develop methods of controlling the gradients, water modeling has been conducted. The water modeling was completed in November, 1991, and a detailed report is in preparation.

A comprehensive one-half scale of the pilot smelter was built at uss Technical center and is shown schematically in Figure 28 . Different water (metal) and oil (slag) barrier designs were tested. Mathematical models were developed to determine the backmixing flow rate $\left(Q_{B}\right)$ from input of a tracer into either zone. The backmixing rate was measured as a function of forward flow rate $\left(Q_{f}\right)$, bottom gas flow rate $\left(Q_{\mathrm{Bg}}\right)$, top gas flow rate $\left(\mathrm{V}_{\mathrm{T}_{\mathrm{g}}}\right)$, and barrier design. The concentration in the water phase was measured using a $\mathrm{KCl}$ solution tracer and five conductivity probes. The concentration in the oil phase was measured colorimetrically.

Future work will involve the development of a physical chemical model using the ore and coal inputs, the rates of reduction, and 


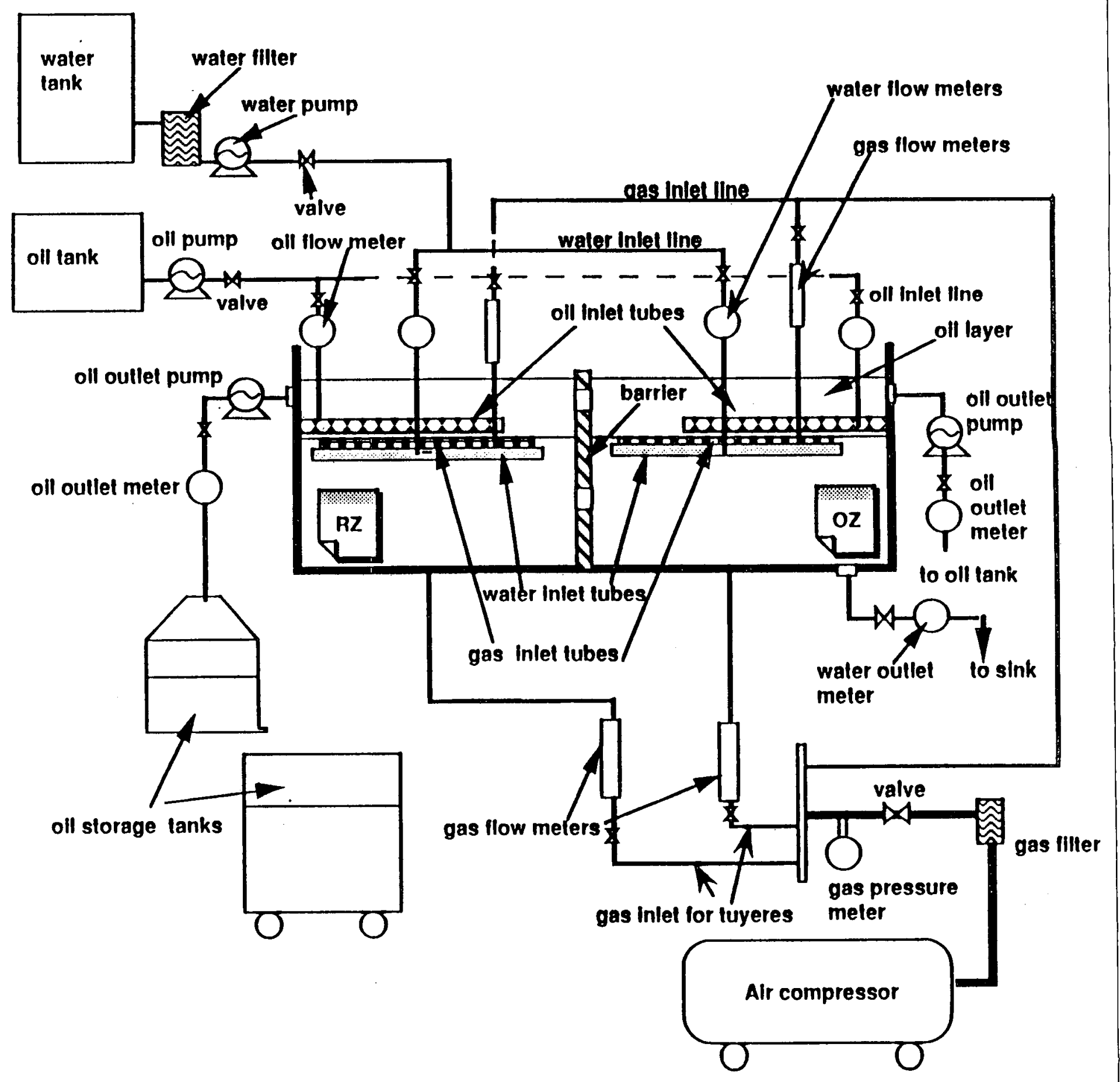

Physical model of two zone smelter 
the results of this study to compute the concentration gradients in the actual operation. The results of this study will be extrapolated to the actual smelting conditions using dimensional analysis.

\section{TASK 9 - DESIGN AND CONSTRUCTION OF THE HORIZONTAL GMELTER}

As reported last year, the Project Management Board, on December 14, 1990, authorized the continuance of work on the horizontal smelter and gave authority to proceed with the placing of orders for the major components for the project.

During January, 1991, and through to the early spring, the engineering proceeded at a rapid pace, specifications were produced for the major mechanical and electrical components, bids were received, and contracts were let to the selected suppliers. By mid-May the two major construction packages were out for bid, and shortly thereafter the contractors were selected and contracts awarded.

A schedule was developed to accommodate vertical vessel operation through August. It called for work to be started in early July and required working on a four-day, ten-hour schedule to ensure minimum interference with the ongoing operation. A significant amount of construction work was accomplished prior to shutdown.

The pilot plant was shut down by the operators at the end of August, and the three-month construction period started. Full mobilization of construction forces occurred immediately, and concentrated expediting of equipment not on site was undertaken.

Careful site management resulted in the construction of the horizontal vessel and ancillary equipment moving ahead rapidly, despite some unforeseen difficulties with the major fabrications. 
A large amount of the required platforms, walkways, access ladders, etc., were installed to field sketches to meet the requirements and satisfaction of the operators.

By mid-November commissioning of the equipment was underway, and the completed plant was handed over to the operations personnel to start refractory dryout procedures and equipment checkout in the first week of December.

Thus, the project was completed on schedule and, it should be noted also, slightly below budget.

\section{TASK 10 - DESIGN OF A MOVING-BED SHAFT REDUCER}

The envisioned Direct steelmaking flowsheet will employ a movingbed shaft reducer using conditioned smelter offgas to preheat and prereduce to the wustite state (about $30 \%$ of the oxygen is removed) iron ore pellets for subsequent use in the smelter. Although shaft reducers are used around the world to produce highly metallized pellets, the production of wustite represents a new technology. Accordingly, HYLSA of Monterrey, Mexico, who has a shaft pilot plant and good research and development ( $R$ \& D) laboratories and is well-known in direct reduction technology, was contracted to develop a shaft furnace process to produce wustite pellets.

Tests were conducted at HYLSA's pilot plant (can produce about 30 tonnes per day of wustite) using simulated smelter gases at a $40 \%$ postcombustion level and at temperatures of 900 and $950 \mathrm{C}$. Tests were conducted over a wide range of gas flows ranging from 2000 to $800 \mathrm{NM}^{3}$ of gas per tonne of iron produced $\left(\mathrm{NM}^{3} / \mathrm{tFe}\right)$. As shown in Figure 29, the conversion to wustite was reasonably constant over a wide range of gas flows but decreased dramatically at the $800 \mathrm{NM}^{3} / \mathrm{tFe}$ gas flow rate. HYLSA estimates that the minimum gas flow for good conversion to wustite is about $1050 \mathrm{NM}^{3} / \mathrm{tFe}$. This pilot plant information, in conjunction with laboratory tests, has enabled HYLSA to develop a mathematical model for a wustite shaft 





furnace that can be used to predict the reduction level as a function of reducing gas composition, temperature, and flow.

Based on information from the $R$ and $D$ program, HYLSA has developed the functional engineering specifications for a pilot plant reduction shaft furnace that may be installed at the Direct steelmaking pilot plant at Universal. This information is adequate to permit the detailed design of the shaft furnace to be completed. Furthermore, HYLSA has provided the preliminary design specifications for a shaft furnace to supply wustite to a proposed demonstration plant to produce 50 tonne per hour of hot metal.

\section{TASR 12 - MANNESMANN DEMAG BASIC STUDY}

To create a technical and economic basis for the further development of a commercial size plant, Mannesmann Demag (MD) was retained to prepare an independent and comprehensive feasibility study for the industrial scale application of the AISI direct ironmaking process with the objective of constructing a 350,000 ton per year demonstration plant on the site of a host company still to be identified.

The study was divided into two stages. The first stage was to be a basic study and the second stage a detailed feasibility study, if warranted by the results of the basic study. The basic study consisted of a critical survey of the results gained from the trial runs and from theoretical computations. It also included the determination of a preliminary plant concept with rough estimated costs and rough feasibility evaluation.

The Mannesmann Demag study concluded that AISI has demonstrated the technical operability of the smelting process for direct ironmaking in one year of pilot plant operation. 
The critical survey, utilizing MD developed software for calculation of smelting reduction processes, showed that the inbath smelting process can be equivalently described both by the AISI model and the MD model.

The postcombustion of about $40 \%$ of the process gas within the high foaming slag in the BOF-type smelter leads to an autothermic and thermally well-balanced process.

Prereduction of the iron ore pellets for the smelter pilot plant at Universal will be performed by the very well-proven HYL gas-based direct reduction process, which technology has been specially modified to fulfill AISI process requirements, i.e. using offgases from the smelter.

Based on extensive tests with iron ore pellets from Inland steel in the moving-bed pilot shaft furnace in Monterrey, HYLSA's conclusions are that the preheating and prereduction of hematite to wustite is viable, when the specific gas flow and the temperature of the smelter offgas are above $1,025 \mathrm{Nm}^{3} / \mathrm{t}$ Fe and between $900^{\circ} \mathrm{C}$ and $950^{\circ} \mathrm{C}$ respectively.

The scale-up criteria to prepare the basic study are based on the experimental results at Universal and Monterrey and on the assumptions of AISI and HYLSA where proven data have not yet been gathered from pilot plant operation.

The design basis for the proposed plant is a BOF-type smelter vessel and a soft blowing oxygen lance, which can secure a proper distribution of the oxygen over the entire cross section of the vessel.

The following design criteria were selected:

1. Capacity - $50 \mathrm{t}$ hot metal/h

2. Postcombustion - $40 \%$

3. Prereduction to wustite $-27.5 \%$ 
4. Pressurized operation

5. Production rate $4 \mathrm{t} / \mathrm{h} \mathrm{\textrm {m } ^ { 2 }}$

6. Production intensity $10 \mathrm{t} /$ day $\mathrm{m}^{3}$

7. Continuous smelting

8. Batch tapping

9. Refractory wear $0.25 \mathrm{~mm} / \mathrm{h}$

The lower gas velocity, together with a large diameter vessel mouth, will allow proper foaming slag management within a gas-tight converter.

Mannesmann Demag personnel confirmed the favorable AISI technoeconomic analyses with respect to variable operating costs and estimated significantly lower capital costs than for the coke oven, blast furnace route. Their cover letter, accompanying the basic study, stated "the results of the basic study confirm a considerable potential for technoeconomic advantages of the AISI Direct Ironmaking Process" and concluded that it would be "a compact plant concept with high productivity."

Because of the favorable outcome of the basic study, the more detailed feasibility study will be initiated. 
